Cabrera Pacheco, Ana Julia. Estrategias de sustentabilidad en el solar maya Yucateco en Mérida, México. GeoGraphos. [En línea]. Alicante: Grupo Interdisciplinario de Estudios Críticos y de América Latina (GIECRYAL) de la Universidad de Alicante, 2 de enero de 2014, vol. 5, no 56, p. 1- 32 [ISSN: 2173-1276]. [DOI: 10.14198/GEOGRA2014.5.56].

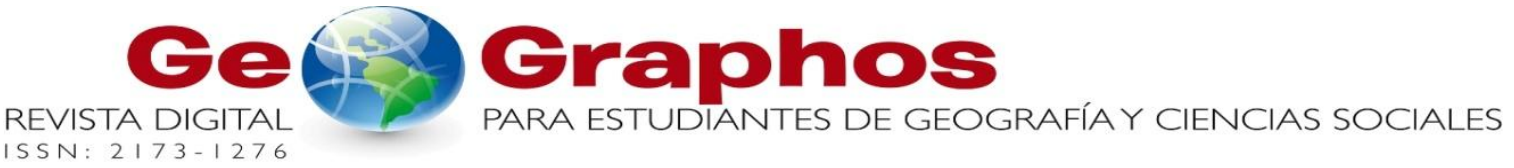

〈http://web.ua.es/revista-geographos-giecryal >

Vol. 5. $\mathrm{N}^{\circ} 56$

Año 2014

\title{
ESTRATEGIAS DE SUSTENTABILIDAD EN EL SOLAR MAYA YUCATECO EN MÉRIDA, MÉXICO
}

\author{
Ana Julia Cabrera Pacheco \\ Doctorado en Geografía \\ School of Geography. University of Leeds (Leeds, Reino Unido) \\ Correo electrónico: gyajcp@leeds.ac.uk
}

Recibido: 23 de mayo de 2013. Aceptado: 2 de enero de 2014

\section{RESUMEN}

El solar es una unidad territorial básica dentro de la tradición maya del Estado de Yucatán, donde se desarrollan múltiples y complejas interacciones sociales, económicas y ambientales. Debido a procesos de cambio culturales, sus elementos tradicionales han dejado de ser primordiales, alterando su equilibrio y modificando las relaciones que en él se dan. El objetivo de este trabajo es identificar las estrategias sociales, económicas y ambientales del solar que coadyuvan a la recuperación de la palma de guano (Sabal spp.) y de la vivienda vernácula. La zona de estudio se sitúa en el área periurbana de la zona metropolitana de Mérida. El análisis se realizó a través de unos indicadores de medios de vida. Los principales resultados muestran que la sustentabilidad del solar se favorece por la diversidad y asociaciones de los recursos naturales, entre otros. Al perderse éstos, se dificulta el desarrollo de medios de vida que sean sustentables. Este trabajo fue desarrollado como proyecto final del Diplomado de Especialista en Gestión Ambiental Urbana y aprobado el 30 de septiembre de 2011. 
Palabras clave: Solar maya yucateco, estrategias, sustentabilidad, medios de vida, palma de guano.

\title{
SUSTAINABLE STRATEGIES IN THE MAYA SOLAR OF YUCATAN IN MERIDA, MEXICO
}

\begin{abstract}
The Solar is a basic territorial unit within the Maya tradition in the State of Yucatan, where multiple and complex social, economic and environmental interactions are developed. Due to processes of cultural change its traditional elements have stopped being primordial; thus, altering its equilibrium and modifying the relations set in it. The objective of this paper is to identify the social, economic and environmental strategies from the Solar that contribute to the recovery of the Guano Palm (Sabal spp.) and of the vernacular housing. The study area is located in the peri-urban region of the metropolitan area of Merida. The analysis was done through livelihood indicators. The main results show that the sustainability of the Solar is favored by the diversity and the associations of the natural resources, among others. When those are lost, the development of sustainable livelihoods becomes complicated. This paper was developed as a final project in the specialization course of Environmental Urban Management and approved on the $30^{\text {th }}$ of September 2011.
\end{abstract}

Keywords: Maya Solar of Yucatan, Strategies, Sustainability, Livelihoods, Guano Palm.

\section{ESTRATÉGIAS DE SUSTENTABILIDADE NO SOLAR MAIAS DE YUCATAN EM MERIDA, NO MEXICO}

\section{RESUMO}

O solar é uma unidade territorial básica dentro da tradição maia de Yucatán, onde existem múltiplas e complexas interações sociais, econômicas e ambientais. Assim como os processos de mudança cultural, os elementos tradicionais já não são primários, perturbando o seu equilíbrio e mudando a relação que é dada. O objetivo deste trabalho foi identificar quais os aspectos sociais, econômicos e as estratégias ambientais sustentáveis no solar que contribuem para a recuperação de guano de palma (Sabal spp.) e da habitação vernacular. A área de estudo situa-se na zona suburbana da região metropolitana de Mérida. A análise foi realizada por meio de indicadores de subsistência. Os principais resultados mostram que a sustentabilidade no solar é promovida, entre outros fatores, pela diversidade e associação dos recursos naturais. Quando isso é perdido se impede o desenvolvimento de meios de subsistência sustentáveis. Este trabalho foi desenvolvido como um projeto final do curso de especialização em Gestão Ambiental Urbana e aprovado em 30 de setembro de 2011.

Palavras-chave: Solar maia de Yucatán, estratégias, sustentabilidade, meios de subsistência, guano de palma. 


\section{INTRODUCCIÓN}

La zona metropolitana de Mérida (ZMM) se localiza en la zona noroeste del Estado de Yucatán en México. Es la mayor zona urbana del Estado, aunque comprende también regiones periurbanas y rurales. Incluye los municipios de Conkal, Kanasín, Mérida, Progreso, Ucú y Umán, con una población total de 1’027,004 habitantes (INEGI, 2010). El solar maya yucateco es una unidad territorial básica en la Península de Yucatán, derivada de la distribución socio-espacial de la civilización maya y modificada durante la época colonial (1521-1821). Es un espacio de múltiples y complejas relaciones sociales, culturales, económicas y ecológicas, donde cada actividad humana tiene un espacio, construido o no, determinado por el uso y la tradición. Las relaciones sociales con otros miembros de la comunidad y el descanso familiar, entre otros, se realizan en la casa-habitación, una construcción tradicional, la vivienda vernácula de los mayas. En la ZMM, esta vivienda está en proceso de desaparición, debido a cambios culturales ocasionados por el crecimiento urbano de las ciudades cercanas y a las decisiones de las instituciones gubernamentales, entre otros. El reemplazo de la vivienda ha ocasionado que la palma de guano ya no sea un elemento primordial en el solar, alterando el equilibrio dinámico del mismo y perjudicando la totalidad del solar, ya que se ha demostrado que el cultivo tradicional de la palma de guano es sustentable. La recuperación de la palma de guano en el solar se percibe como una forma sustentable para contribuir al desarrollo integral de las comunidades mayas ya que al regenerar la biodiversidad del solar se permitirá la recuperación socio-cultural del territorio y la reactivación de la economía familiar, tanto en el corto como en el largo plazo.

El solar ha sido estudiado desde múltiples puntos de vista socio-culturales, agroforestales, arquitectónicos, etc. Sin embargo, dado que ha sido definido como un espacio complejo, se propone un enfoque complejo para su análisis, a través de los indicadores de medios de vida, que abarca múltiples perspectivas derivadas de la sustentabilidad. Por lo tanto, el objetivo general de este trabajo es identificar las estrategias sociales, económicas y ambientales del solar maya yucateco que coadyuvan a la recuperación de la palma de guano (Sabal spp.).

\section{MARCO CONCEPTUAL}

\section{El desarrollo sustentable}

El desarrollo sustentable fue definido por la Comisión Mundial sobre el Medio Ambiente y el Desarrollo, en su informe de 1987 (Informe Brundtland), como "el que satisface las necesidades del presente sin comprometer la habilidad de las generaciones futuras de satisfacer sus propias necesidades" (ONU, 1995-2011). La sustentabilidad implica la existencia de la capacidad para adaptarse a lo largo del tiempo, sin socavar los recursos de los cuales se depende para sobrevivir (DFID, 1999). La sustentabilidad se consigue mediante el equilibrio de los factores que la componen, el factor ambiental, el social y el económico. El concepto de equilibrio debe manejarse como un equilibrio dinámico, congruente con las características del medio ambiente en general. La sustentabilidad ambiental es posible cuando la productividad de los recursos naturales se conserva o se mejora para el uso de las generaciones futuras. La sustentabilidad social se refiere a las relaciones entre grupos específicos de personas e instituciones. La sustentabilidad económica se asocia con el nivel mínimo de bienestar económico y con la capacidad para mantener un nivel determinado de 
ingresos y egresos a lo largo del tiempo (DFID, 1999). Sin embargo, no todas las sociedades tienen acceso a las condiciones que posibilitan la sustentabilidad económica, esto es, la disponibilidad de la fuerza de trabajo, el ambiente y la infraestructura en el momento, lugar, cantidad y calidad correctos. En el momento que las condiciones de producción difieren entre sociedades, la competencia no es equitativa y los bienes ambientales adquieren valores injustos que contradicen la sustentabilidad. Cuando se habla de reducción de la pobreza en términos de la sustentabilidad social, ésta no debe entenderse como un aumento en la capacidad de consumo indiscriminado que iguale la actuación de las sociedades con mayor riqueza, sino como una mejora integral de las condiciones de vida de las personas. Ya que, en pocas palabras, el marco capitalista, del cual deriva el modelo económico actual, perpetúa la in-sustentabilidad social, al no proporcionar medios de vida para todos, y la in-sustentabilidad ambiental, al tender a la acumulación de un bien finito (Cabrera, 2011).

Los desafíos de la sustentabilidad son complejos, ya que también intervienen la cultura y la geografía, entre otros factores. La forma en que una sociedad percibe a la naturaleza impactará su forma de relacionarse con ella. Los sistemas alternativos de producción que han manejado grupos indígenas y de campesinos, de auto-abasto e intercambio, han sido relegados de los sistemas predominantes porque no tienden a la acumulación de recursos ni de bienes. Los sistemas tradicionales están en mejor comunión con el medio ambiente que las rodea, siendo fundamentales el conocimiento de estas comunidades, no sólo del entorno agrícola, sino del entorno natural en general y al no permitírseles desarrollarse de la mano de su cultura, son condenados al fracaso; se pierde la idea básica del desarrollo que señala que cada pueblo debe buscarlo con base en su cultura y debe diferenciarse de los demás, por la unicidad de su identidad cultural (Bartra, 2005; González-Jácome, 2004; Revilla y Reyes, 2005). El territorio es invaluable porque en él se interrelacionan una sociedad y una naturaleza únicas, que han generado procesos de adaptación a lo largo de un tiempo determinado. El valor del ambiente es intrínseco, por tanto su aprovechamiento consciente o su conservación, son primordiales para el sustento de la sociedad y del ambiente mismo.

\section{El marco de medios de vida sustentables}

El marco de los medios de vida sustentables es una herramienta que permite la comprensión de la interacción de los medios de vida familiares con el entorno. Los medios de vida (livelihoods) se describen como una combinación entre los recursos utilizados y las acciones iniciadas con fines de supervivencia; comprenden las posibilidades, activos y actividades necesarias para ganarse la vida. Un medio de vida se considera sustentable cuando es capaz de mantener o mejorar los niveles de vida actuales sin dañar la base de recursos naturales existente, y cuando puede soportar las tensiones y crisis, y recuperarse de los mismos (DFID, 1999; Stewart, 2006). Para comprender la forma como se relacionan los elementos del marco se definen cinco conceptos: el contex to de la vulnerabilidad, los activos de los medios de vida, las instituciones, las estrategias de medios de vida y los resultados de los medios de vida (Figura 1).

El contexto de la vulnerabilidad se refiere a los acontecimientos imprevisibles que afectan los medios de vida de las personas; su característica principal es que no son controlables por los habitantes en el corto y mediano plazo, pudiendo afectar a grupos de personas o a localidades enteras, o únicamente a determinados hogares (DFID, 1999; Stewart, 2006). Los activos (o 
capitales) de los medios de vida se refieren a la base de recursos que posee el hogar o la comunidad para garantizar su supervivencia (Stewart, 2006); se dividen en cinco categorías: humano, físico, económico (o financiero), social y natural (o ambiental). El capital humano es representado por las destrezas, el conocimiento, la capacidad de trabajo y la buena salud, que en conjunto permiten actuar según diferentes estrategias de vida y lograr resultados. El capital físico comprende la infraestructura básica y los activos físicos que apoyan a las personas a satisfacer sus necesidades básicas y a ser más productivas. El capital económico comprende los recursos financieros que las personas utilizan para lograr sus objetivos de medios de vida. El capital social se refiere a las relaciones de las cuales derivan oportunidades y beneficios en el logro de los medios de vida. El capital ambiental comprende la existencia de recursos naturales de los cuales dependen las personas (DFID, 1999). Las instituciones y las políticas son factores externos importantes que influyen en las opciones de medios de vida de las personas, así como en el acceso a los capitales y en el nivel de vulnerabilidad en las crisis. Las estrategias de medios de vida son las combinaciones de actividades y opciones que eligen las personas para alcanzar sus objetivos de sus medios de vida. La combinación total de las actividades que un grupo establece para asegurar una forma de ganarse la vida se conoce como sistema de medios de vida. Los resultados de los medios de vida son los que se logran a través de las estrategias desarrolladas, como son los niveles de seguridad alimentaria, la seguridad en los ingresos, la salud, etc. Los aspectos negativos como la inseguridad y la alta vulnerabilidad conducen a la pérdida de capitales y a la pobreza (Stewart, 2006).

\section{Figura 1. Los medios de vida sustentables}

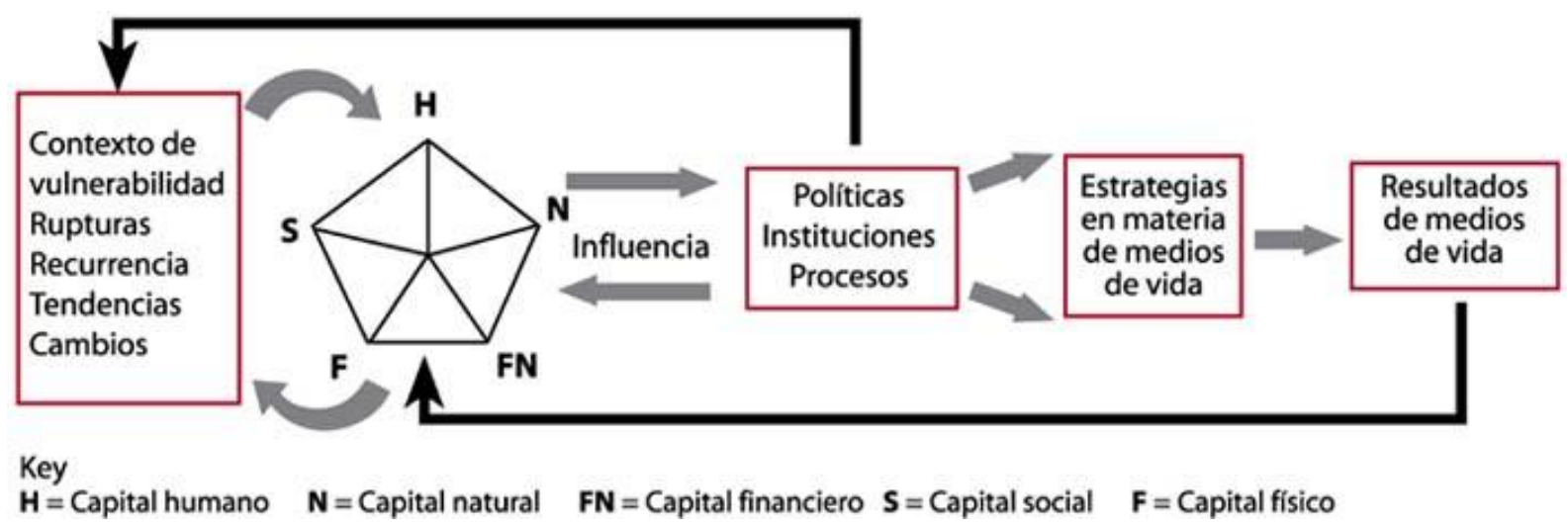

Fuente: Stewart Carloni (2006).

\section{El solar y la vivienda vernácula}

En México, el territorio es un elemento cultural importante para los grupos indígenas, desde la forma como es percibido hasta la forma como es organizado para hacer uso de él. El territorio se considera parte de la cultura, necesario para la continuidad biológica y social de los grupos propios del país (Estrada et al., 1998). Los solares son complejos sistemas tradicionales de producción agrícola. Son también unidades ambientales del paisaje natural transformado; destinados principalmente a cubrir las necesidades de subsistencia de la familia, ya que garantizan acceso directo, debido a su ubicación alrededor de la vivienda y bajo el manejo familiar, a una gran variedad de productos tanto alimentarios como de construcción, utensilios 
y forraje para los animales domésticos. Asimismo, representan una fuente de ingresos para las familias a través de la venta de los productos cultivados o los animales domésticos criados (Correa, 1997; Jiménez-Osornio et al., 1999). Desde el punto de vista social y cultural, el solar tiene la función de proveer cohesión a la unidad familiar y a la comunidad misma a través de acciones de preservación, enriquecimiento y difusión del conocimiento de sus propios habitantes, como ejemplo, se menciona que los solares son laboratorios experimentales, donde se conserva el genoplasma in situ y se realiza una selección artificial de diversas especies. En el solar se desarrollan estrategias para proveer a la familia de productos diversos y generar excedentes económicos; también se desarrollan modelos agroforestales "alternativos" en el manejo de productos bióticos, ya que se reducen los insumos externos y se hace un uso integral y sustentable de los recursos propios del solar (Aké et al., 1999).

En algunos casos, los solares tradicionales se identifican con la presencia de una casahabitación también tradicional o vernácula. La vivienda vernácula es un elemento que sintetiza las respuestas regionales hacia las necesidades habitacionales, sus características han creado ambientes particulares que han conformado identidades específicas de grupos de personas específicas. Para definir la vivienda vernácula se identifican sus características: se basa en el dominio de técnicas y sistemas de construcción ancestrales, resultado de tradiciones acumuladas históricamente y transmitidas generacionalmente; se construye con materiales naturales de la región, que se incorporan al ciclo ecológico una vez que dejan de ser útiles; y, es producida por los mismos usuarios (auto-construcción) o miembros de la misma comunidad, lo que fomenta las relaciones sociales en la comunidad (Chico, 1995; Tello, 1995). La vivienda vernácula está fuertemente ligada con las actividades que en ellas se practican, así como con el uso del espacio y las cualidades ambientales específicas. Cuando éstas se modifican, se influye en la imagen y características específicas de la vivienda (Tello, 1995). Esta influencia se extiende hacia los solares, ya que generalmente de ahí provienen los materiales con que la vivienda es construida y habitada; también forma parte del espacio extendido de la vivienda, donde se realizan las actividades complementarias.

\section{MARCO METODOLÓGICO}

El presente trabajo fue desarrollado como un documental. Se recopiló información de diversas fuentes para establecer las condiciones y características de los solares mayas yucatecos y para establecer el papel de la pérdida y de la recuperación de la palma de guano. Para el análisis de esta información y su integración, se utilizó el marco de medios de vida sustentable ya que provee tanto las bases para entender la naturaleza de la situación integral (social, económica y ambiental, entre otras) de una comunidad, como para identificar los tipos de estrategias que podrían mejorarla en una forma efectiva y sustentable utilizando diferentes tipos de activos (Robles-Zavala y Fiechter, 2008). 
Cuadro 1. Valores de los indicadores de medios de vida

\begin{tabular}{|c|c|c|c|}
\hline Categoría & Indicador & Respuestas & $\begin{array}{l}\text { Valor } \\
\text { asignado }\end{array}$ \\
\hline \multirow{13}{*}{$\begin{array}{l}\text { Capital } \\
\text { humano }\end{array}$} & Alfabetismo & $\mathrm{Si} / \mathrm{No}$ & $5 / 0$ \\
\hline & Lengua indígena & $\mathrm{Si} / \mathrm{No}$ & $5 / 0$ \\
\hline & $\begin{array}{l}\text { Distribución de } \\
\text { edades }\end{array}$ & $\begin{array}{l}\text { Varias combinaciones de niños, jóvenes, } \\
\text { adultos y adultos mayores }\end{array}$ & $5 / 3 / 1$ \\
\hline & \multirow[t]{6}{*}{ Derechohabiencia } & $\mathrm{Si}(100 \%)$ & 5 \\
\hline & & $\mathrm{Si}(80-99 \%)$ & 4 \\
\hline & & Si $(60-79 \%)$ & 3 \\
\hline & & $\mathrm{Si}(40-59 \%)$ & 2 \\
\hline & & $\mathrm{Si}(20-39 \%)$ & 1 \\
\hline & & $\mathrm{Si}(0-19 \%)$ & 0 \\
\hline & \multirow[t]{4}{*}{ Escolaridad } & Mayor a la primaria & 5 \\
\hline & & Primaria & 3 \\
\hline & & Sin primaria completa & 1 \\
\hline & & Sin instrucción & 0 \\
\hline \multirow{12}{*}{$\begin{array}{l}\text { Capital } \\
\text { físico }\end{array}$} & \multirow{6}{*}{$\begin{array}{l}\text { Disponibilidad de } \\
\text { agua entubada }\end{array}$} & Dentro de la vivienda & 5 \\
\hline & & $\begin{array}{l}\text { Fuera de la vivienda pero dentro del } \\
\text { terreno }\end{array}$ & 4 \\
\hline & & Llave pública & 3 \\
\hline & & Acarreo de otra vivienda & 2 \\
\hline & & Pipa & 1 \\
\hline & & Agua de pozo artesanal & 0 \\
\hline & \multirow[t]{3}{*}{$\begin{array}{l}\text { Disponibilidad de } \\
\text { servicios }\end{array}$} & $\begin{array}{l}\text { Disponibilidad de sanitario y de conexión } \\
\text { eléctrica }(100 \%)\end{array}$ & 5 \\
\hline & & Un servicio $(50 \%)$ & 3 \\
\hline & & Ningún servicio $(0 \%)$ & 0 \\
\hline & Hacinamiento & 0-2.9 / 3 o más personas/cuarto & $5 / 0$ \\
\hline & Material del piso & Material "durable" / Tierra & $5 / 0$ \\
\hline & $\begin{array}{l}\text { Disponibilidad de } \\
\text { refrigerador }\end{array}$ & $\mathrm{Si} / \mathrm{No}$ & $5 / 0$ \\
\hline \multirow{12}{*}{$\begin{array}{l}\text { Capital } \\
\text { económico }\end{array}$} & \multirow[t]{4}{*}{ Habitantes ocupados } & Tiene trabajo & 5 \\
\hline & & Jubilado o pensionado & 3 \\
\hline & & $\begin{array}{l}\text { Estudiante y persona que se dedica a los } \\
\text { quehaceres del hogar }\end{array}$ & 1 \\
\hline & & $\begin{array}{l}\text { Busca trabajo, está incapacitado } \\
\text { permanentemente para trabajar y no trabaja }\end{array}$ & 0 \\
\hline & \multirow{4}{*}{$\begin{array}{l}\text { Índice de } \\
\text { dependencia }\end{array}$} & $0.9-1$ & 5 \\
\hline & & $0.6-0.8$ & 3 \\
\hline & & $0.3-0.5$ & 1 \\
\hline & & $0.0-0.2$ & 0 \\
\hline & \multirow[t]{4}{*}{ Total de ingresos } & Más de 5 S.M. & 5 \\
\hline & & 2.1-5 S.M. & 3 \\
\hline & & 1-2 S.M. & 1 \\
\hline & & Menos de 1 S.M. & 0 \\
\hline
\end{tabular}




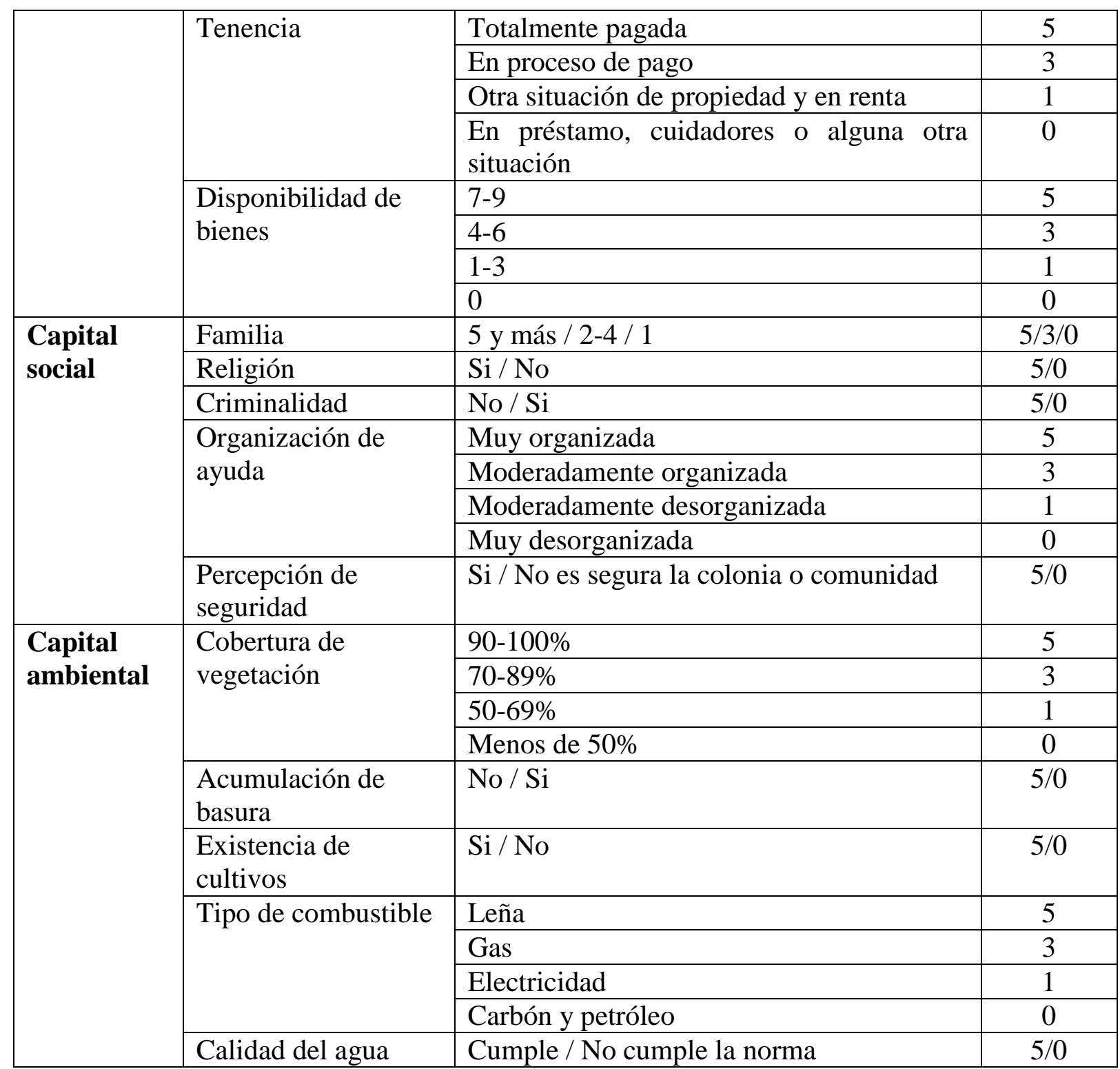

Fuente: Elaboración propia.

\section{Indicadores de medios de vida}

Partiendo del marco de los medios de vida y sus capitales se desarrolló una serie de indicadores para cada capital, con el fin de determinar las características del solar maya yucateco. Se tomaron como unidades de análisis viviendas de las localidades elegidas que tuvieran techo de palma ${ }^{1}$. Se eligieron al azar cinco viviendas por localidad, de tal manera que sea viable su análisis a nivel de vivienda y población; sin embargo, para dos localidades (Chablekal y San José Tzal), las viviendas no fueron suficientes, por lo que el número final de viviendas analizadas fue 25 . Se determinó que el número de indicadores representativos por

\footnotetext{
${ }^{1}$ Según el Instituto Nacional de Estadística y Geografía con datos del XII Censo General de Población y Vivienda (2000).
} 
capital fuera cinco, cuya puntuación se agregó para determinar la puntuación del capital y proceder a su análisis. Los indicadores fueron analizados por habitante de la vivienda o por vivienda según correspondía. Las clasificaciones finales se encuentran en el cuadro 1.

Cabe señalar que al momento de realizar este estudio no se contaba con la información del Censo de Población y Vivienda 2010 del Instituto Nacional de Estadística y Geografía (INEGI) a nivel registro. La información del Conteo 2005 no contempla todos los rubros que este estudio requería, por lo que se decidió utilizar la información del XII Censo General de Población y Vivienda (Censo 2000) del INEGI que proveía suficiente información para desarrollar los temas requeridos a nivel vivienda y habitante. Se realizó, además, un análisis a nivel localidad que abarcó la situación de cada una de ellas a nivel general, sin hacer distinción acerca de las viviendas. Para este análisis se utilizó la información de los "Principales resultados por localidad" (INEGI, 2010a) y las "Encuestas Nacionales de Gastos e Ingresos de los Hogares" (INEGI, 2010b), que permitieron realizar análisis de los años 2000 y 2010 para observar los posibles cambios en las localidades. Sin embargo, la información de ambos Censos no es compatible al cien por ciento, por lo que en algunos casos se hicieron aproximaciones. En los casos que la información no se tomó del INEGI, la información existía únicamente a nivel localidad o municipal.

\section{Capital humano}

Los indicadores del capital humano nos indican las características de los habitantes de la vivienda (Cuadro 1). La información para estos indicadores proviene del Censo 2000. Las variables dicotómicas por habitante fueron promediadas para obtener un valor a nivel vivienda.

1) El alfabetismo se refiere a la persona que sabe leer y escribir; es una variable dicotómica a nivel habitante. "El acceso al conocimiento constituye un aspecto crucial para que las personas estén en condiciones de realizar el proyecto de vida que tienen razones para valorar" (Anzaldo y Prado, 2007, p. 13).

2) La condición de hablante de lengua indígena fue considerada como una destreza o un valor agregado; es una variable dicotómica a nivel habitante.

3) La distribución de edades se consideró como la capacidad para distribuir las actividades en un solar, esto es, entre niños, jóvenes, adultos y adultos mayores. Se hicieron varias combinaciones con los grupos de edades de los habitantes, para dar una puntuación a la vivienda. Por ejemplo, una vivienda donde hubiera habitantes niños, jóvenes, adultos y adultos mayores, tendría la máxima puntuación, mientras que una vivienda donde viviera únicamente un adulto mayor, tendría la menor puntuación.

4) La derechohabiencia se refiere a la pertenencia de la persona a algún servicio de salud público como el Instituto Mexicano del Seguro Social (IMSS); es una variable dicotómica a nivel habitante.

5) La escolaridad hace referencia a los estudios primarios, ya que según el Consejo Nacional de Población (Conapo): "La mayor intensidad de la marginación social, derivada de la falta 
de participación y permanencia por más tiempo en el sistema educativo, se registra en la población que carece de los conocimientos que pueden adquirirse en la educación primaria, cuya desventaja se acentúa entre los adultos" (Anzaldo y Prado, 2007, p. 13); se otorgó puntuación a cada habitante mayor de 12 años (edad mínima para terminar la educación primaria) y posteriormente se hizo un promedio para tener una puntuación por vivienda.

\section{Capital físico}

Los indicadores del capital físico nos indican las características de la vivienda (Cuadro 1). La información para estos indicadores proviene del Censo 2000.

1) La disponibilidad del agua potable se refiere al origen y la disposición del agua en la vivienda. Se dio puntuación a la vivienda según el tipo de acceso al agua. El acceso al agua segura implica una menor carga en las familias y menos enfermedades relacionadas con el agua, así como la mejora en la calidad de vida, si es asequible y en cantidades suficientes (UN-Habitat, 2009).

2) La disponibilidad de servicios engloba la disponibilidad de servicio sanitario y de electricidad en la vivienda, se calculó según si se contaba con los dos servicios, sólo con uno o con ninguno. La falta de sanidad es un problema público serio ya que causa enfermedades y muerte (UN-Habitat, 2009). La falta de energía eléctrica priva a la población del acceso a luz artificial corriente, entre otras cosas (Anzaldo y Prado, 2007).

3) El hacinamiento se definió como la existencia de área suficiente para vivir en una vivienda por cada uno de sus habitantes y se calculó con el número de personas entre los cuartos disponibles para dormir, es una variable dicotómica. Hasta 3 personas por cuarto se considera a la vivienda como "no hacinada" y más de 3 personas por cuarto se considera "hacinada" (UN-Habitat, 2009).

4) El material de piso se refiere a si el piso de la vivienda era de tierra o de otro material (cemento, mosaico, madera, etc.), es una variable dicotómica. El piso de tierra es un elemento que incide en la salud de las personas, sobre todo en los niños pequeños (Anzaldo y Prado, 2007).

5) La disponibilidad de refrigerador se refiere a la importancia de contar con un medio para conservar los alimentos por mayor tiempo en buen estado (Anzaldo y Prado, 2007), es una variable dicotómica.

\section{Capital económico}

Los indicadores del capital económico nos indican las características a nivel de la vivienda (Cuadro 1). La información para estos indicadores proviene del Censo 2000.

1) La ocupación de los habitantes de la vivienda se calculó según si por dicha ocupación aportaban ingresos monetarios o algún otro tipo de beneficio. A cada habitante se le asignó un valor que luego se promedió para tener un valor por vivienda. 
2) El Índice de dependencia se refiere a las personas que no trabajan por cada trabajador (Cortés y Hernández-Laos, 2002), se calculó con el número de personas que aportaban ingresos monetarios entre todos los que vivían en la vivienda.

3) El total de ingresos se refiere al ingreso mensual por vivienda. Según Anzaldo y Prado (2007), la marginación se considera hasta de dos salarios mínimos y según el Banco de México (Banxico, 2009), aproximadamente la mitad de la población en México tiene ingresos entre más de dos y cinco salarios mínimos. Se sumaron los ingresos de todos los habitantes de la vivienda para hacer los cálculos correspondientes.

4) La tenencia de la vivienda se refiere a la legalidad de la ocupación de dicha vivienda. La tenencia segura se considera como el primer componente para lograr paulatinamente el derecho a una vivienda digna (UN-Habitat, 2009). Se calculó según los diversos tipos de tenencia.

5) La disponibilidad de bienes se refiere a una forma de propiedad o de valor económico "en especie"; refleja la capacidad de adquisición y va más allá de obtener ingresos para la supervivencia diaria. Se otorgó puntuación de acuerdo al número de bienes reportados.

\section{Capital social}

Los indicadores del capital social nos indican las características de los habitantes de la vivienda (Cuadro 1). La información para estos indicadores proviene del Censo 2000 y de la Primera Encuesta Metropolitana (PEM) $2010^{2}$ (OMY, 2010). Las variables dicotómicas por habitante fueron promediadas para obtener un valor a nivel vivienda; mientras que las variables disponibles a nivel vivienda general, se promediaron para obtener valores a nivel localidad.

1) La existencia de familia se refiere a los lazos de apoyo que cada habitante tiene dentro de su propia vivienda. Se tomó como base cinco habitantes, el promedio de habitantes en las viviendas con techo de palma de las localidades seleccionadas, las cuales obtuvieron la mayor puntuación, mientras que las viviendas con un habitante, obtuvieron la menor.

2) La pertenencia a una religión se refiere al apoyo social que tiene el individuo dentro de la organización religiosa; es una variable dicotómica a nivel habitante.

3) La criminalidad se refiere a si algún habitante de la vivienda ha experimentado algún tipo de crimen; es una variable dicotómica promediada a nivel localidad.

4) La organización de la ayuda en la comunidad se refiere a la percepción que tienen los habitantes de la organización de su propia comunidad. Es una variable promediada a nivel localidad.

\footnotetext{
${ }^{2}$ La PEM2010 se utilizó a nivel localidad, para las localidades de Caucel, Chablekal, Conkal, San José Tzal y Ucú; la localidad de Komchén se calculó mediante la interpolación con el dato de población total entre Caucel y Chablekal (sus inmediatos superior e inferior).
} 
5) La percepción de la seguridad en la colonia y la comunidad se refiere a la clasificación de los habitantes de la vivienda a su propia percepción de la seguridad en el medio donde viven. Es una variable promediada a nivel localidad.

\section{Capital ambiental}

Los indicadores del capital ambiental nos indican las características a nivel de la vivienda y del espacio donde se localiza la vivienda. La información para estos indicadores proviene del Censo 2000, de la PEM 2010, de los Indicadores Urbanos de la ZMM (García Silberman, 2011) y de estudios hidrogeológicos y de calidad del agua subterránea en la ZMM (Pacheco y Cabrera, 2001; Pacheco, 2011). Las variables disponibles a nivel vivienda general, se promediaron para obtener valores a nivel localidad

1) El porcentaje de cobertura de vegetación en el municipio se refiere a la importancia que se ha dado a la conservación de la vegetación en el municipio al que pertenecen las localidades. A mayor presencia de vegetación podría permitirse un mayor desarrollo sustentable de las localidades.

2) La acumulación de basura se refiere a si los habitantes de la vivienda han percibido durante el último año la acumulación de basura en la calle donde se encuentra su vivienda. Es una variable promediada a nivel localidad.

3) La existencia de cultivos de los habitantes de la vivienda se refiere a la capacidad de los habitantes de sacar provecho al terreno de su vivienda o a algún otro terreno para cultivar alimentos. Es una variable promediada a nivel localidad.

4) El tipo de combustible utilizado en la vivienda se refiere a la capacidad de dicho combustible de ser manejado de forma sustentable por la propia vivienda. Se calculó de acuerdo a la puntuación de cada tipo de combustible.

5) La calidad del agua se refiere a tres parámetros de calidad del agua analizados en el agua entubada que llega a las viviendas. Cabe señalar que el agua fue analizada antes que fuera tratada con cloro (ya que no se potabiliza), por lo que llega a las viviendas en condiciones óptimas para su consumo. Se analizaron el Ion cloruro, el Ion nitrato y los organismos coliformes fecales. Cada uno se consideró una variable dicotómica (cumple o no cumple la norma correspondiente) y se calculó con el promedio de la puntuaciones obtenidas en cada localidad. Los datos de la localidad de Caucel se calcularon con los de Ucú debido a su cercanía física.

\section{ZONA DE ESTUDIO}

\section{La Zona Metropolitana de Mérida, México}

En México, la formación de zonas metropolitanas se ha dado desde 1940 por la expansión física de las ciudades sobre el territorio de dos o más municipios o estados. Actualmente, las características de una zona metropolitana involucran interrelaciones económicas, sociales, 
ambientales, políticas y territoriales que impactan a la zona como un todo y no únicamente a la ciudad (SEDESOL et al., 2004; COMEY, 2007-2012). La Zona Metropolitana de Mérida (ZMM) (Figura 2) se localiza en el estado de Yucatán, en el sureste de México. Comprende los municipios de Conkal, Kanasín, Mérida, Progreso, Ucú y Umán (COMEY, 2007-2012). La ZMM tiene una población total de 1'027,004 habitantes. Las localidades urbanas han sido definidas por el INEGI como las que tienen una población igual o mayor a 2,500 habitantes de acuerdo al último Censo o Conteo Nacional de Población y Vivienda y a todas las cabeceras municipales aunque no alcancen este rango de población (SEDESOL et al., 2004). En la ZMM, todas las cabeceras municipales cumplen con ambos requisitos, aunque con notables diferencias entre ellas. La capital del estado de Yucatán es la ciudad de Mérida, con una población de casi 800 mil personas, seguida por las ciudades de Kanasín y Umán, que se encuentran conurbadas físicamente a la ciudad de Mérida, con casi 80 mil y 40 mil personas, respectivamente. El puerto de Progreso tiene una población similar a la de Umán y se encuentra a $33 \mathrm{~km}$ de la ciudad de Mérida (SCT, 2011). Las cabeceras de Conkal y Ucú son considerablemente menores, con poblaciones de aproximadamente 7 mil y 2,500 habitantes, y con distancias de 15 y $24 \mathrm{~km}$ aproximadamente de la ciudad de Mérida, respectivamente (SCT, 2011; INEGI, 2010a).

A pesar de su clasificación como asentamientos urbanos, algunas localidades presentan ciertas características rurales, específicamente en sus dinámicas socio-económicas. Estas localidades se consideran periurbanas. El concepto de periurbano se refiere a la zona de difusión urbanorural o incluso rural donde se desarrollan prácticas económicas y sociales ligadas a las dinámicas de las ciudades. Los espacios metropolitanos ponen en entredicho las concepciones duales y las funciones tradicionales del campo y la ciudad. Hay zonas marcadamente rurales distantes de los núcleos que tienen mayoría de actividades no agrícolas o cuentan con todos los servicios urbanos característicos de las ciudades. La expresión de la periurbanización se da a través de anillos concéntricos dispuestos alrededor de las ciudades, que pertenecen al concepto de ciudad difusa a partir de las relaciones entre las ciudades pequeñas y medianas entre ellas mismas y con la ciudad central (Delgado et al., 2008; Ávila, 2009). La ciudad de Mérida ha ido expandiéndose mediante círculos concéntricos durante varias décadas, al principio partiendo del centro histórico hacia el primer anillo llamado Circuito Colonias, y desde ahí hasta llegar al Anillo Periférico. Hoy en día, éste ha sido rebasado, principalmente por industrias, centros educativos y fraccionamientos masivos, estando en planes la creación de un Anillo Vial Metropolitano que uniría varias localidades de cinco municipios.

Para este estudio, se tomaron en cuenta las localidades de la ZMM mayores a 2,500 habitantes que no se encuentran conurbadas con la ciudad de Mérida ni con el puerto de Progreso, es decir, las localidades periurbanas. Con base en la información de población del Censo 2010 (INEGI, 2010a) se identificaron seis localidades: Caucel, Chablekal, Conkal, Komchén, San José Tzal y Ucú (Figura 3). 
Figura 2. Zona Metropolitana de Mérida

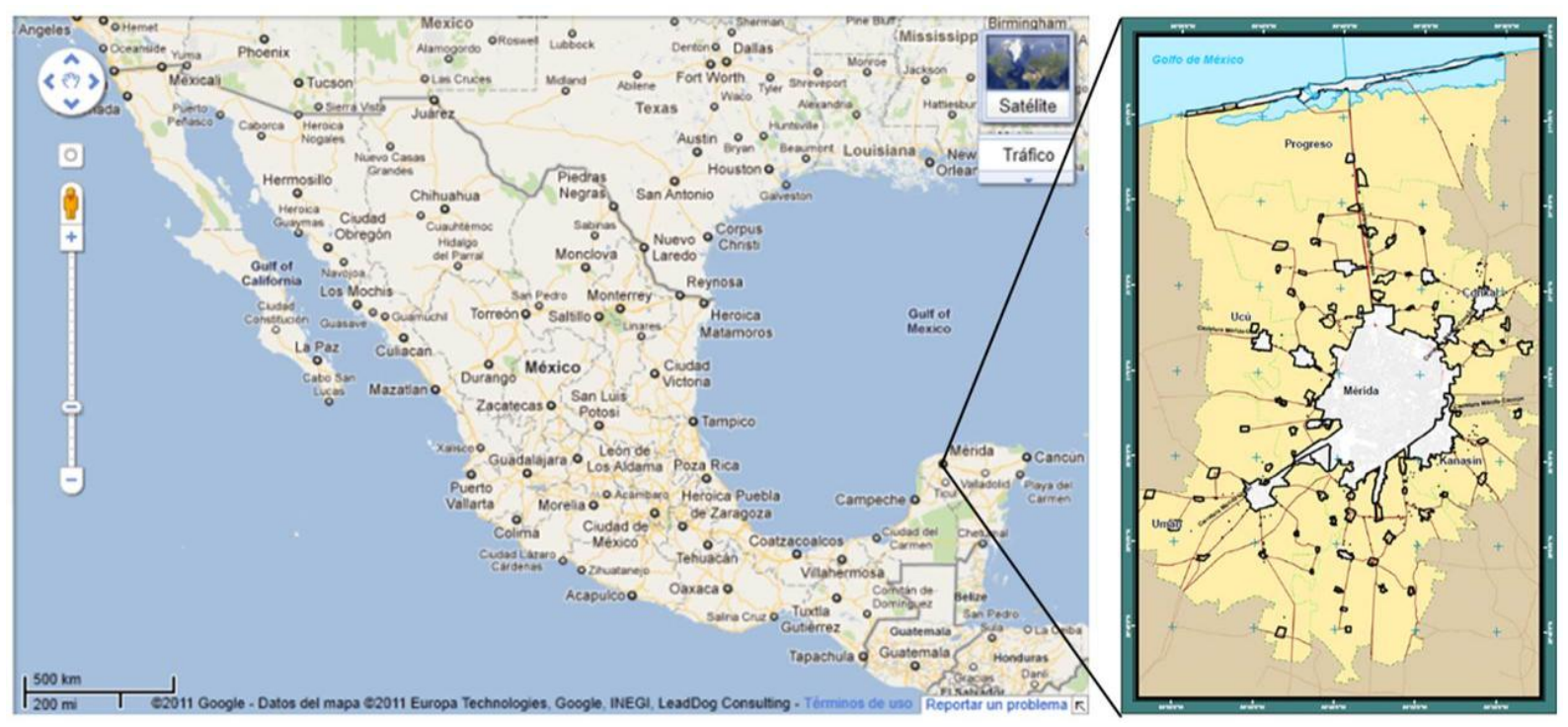

Fuente: Google (2011) y OMY (2011).

\section{El solar maya yucateco}

De acuerdo con Cardoso (en Bracamonte y Sosa y Lizama Quijano, 2003), la identificación de un individuo como parte de un grupo étnico específico no es fácil debido a la manera en que las personas se identifican a sí mismas, así como al hecho que la identidad no es necesariamente una consideración natural sino una construcción social. En regiones como la Península de Yucatán, la dicotomía tradicional de sociedad indígena y sociedad mestiza, tradicional a nivel nacional, no está bien definida. Los elementos que podrían demarcar una categoría de otra se encuentran continuamente mezclados: el idioma, el vestido y las características físicas, entre otros. A nivel nacional, sin embargo, el indicador comúnmente aceptado para identificar a los individuos de un grupo indígena que viven dentro del territorio nacional es el idioma. En Yucatán, 544,927 personas hablan alguna lengua indígena, que representa un 28\% de la población; de las cuales, el $90 \%$ también hablan español; en la ZMM, el $11 \%$ de la población habla lengua indígena (INEGI, 2010a).

La representación física contemporánea de la cultura maya se manifiesta en el lugar donde viven. La vivienda vernácula maya en Yucatán es parte inherente del solar y viceversa. Esto es, que la vivienda tradicional maya yucateca no es únicamente la casa-habitación, sino el solar como un todo. El solar maya yucateco ha formado parte del manejo integrado de recursos que han realizado las comunidades mayas durante milenios. La distribución espacial del ámbito doméstico de los antiguos mayas fue dispersa, esto es, los límites territoriales no eran nítidos; durante el periodo colonial, la tierra disponible fue dividida en solares, que seguían la traza de las calles (Baños, 2003). 


\section{Figura 3. Localidades seleccionadas de la Zona Metropolitana de Mérida}

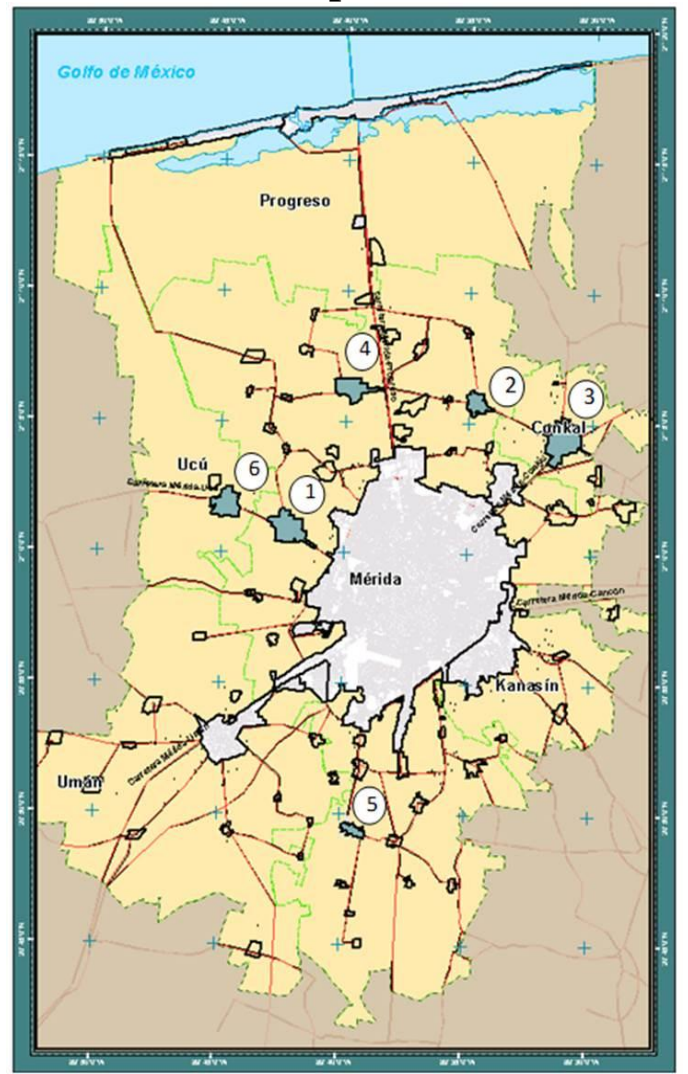

Fuente: Modificado de OMY (2011).

Tradicionalmente, el solar maya yucateco es el predio o terreno, de entre 250 y 1,000 metros cuadrados, donde se realizan la mayor parte de las actividades de la familia maya en Yucatán, separados del exterior por medio de una albarrada ${ }^{3}$. Se constituye principalmente por la casahabitación, algunas construcciones pequeñas y un área abierta, que se delimita por las actividades que en ella se realizan. Según diversos autores (Aké et al., 1999; Tello, 1995; Chico, 1995; Estrada et al., 1998; Ayllón, 2003; Sánchez et al., 2011), el solar se conforma tradicionalmente con los espacios descritos a continuación (Figura 4).

El hogar $(\mathrm{Naj})^{4}$ es el espacio para el descanso familiar y la realización de actividades sociales, religiosas y artesanales, así como el aseo personal. La cocina (K'oben) es un cuerpo secundario o anexo a la construcción principal, tradicionalmente, el techo de esta construcción es de madera y palma de guano y los muros de bajareque sin recubrimiento o embarro (coloxché), que permite que el humo de la cocina se disperse. Es un espacio esencial para la vida cotidiana, ya que gran parte de las actividades están relacionadas con él. Cuenta con un fogón usualmente constituido de tres piedras entre las que se coloca la leña para producir fuego. El troje (Ch'iil) es una estructura de madera para almacenar el maíz, se utiliza más en las áreas

\footnotetext{
${ }^{3}$ Muro bajo de piedras sobrepuestas que se asientan sin mortero.

${ }^{4}$ La palabra en cursivas es el nombre en maya yucateco.
} 
del Estado donde el sistema milpa complementa al sistema del solar. El semillero ( $K$ 'anché) es una estructura elevada para almacenamiento de mazorcas de maíz, siembra de hortalizas y plantas medicinales. Se utiliza como apoyo para el manejo de cultivos y como semillero de plántulas de otras especies mayores. Actualmente se ha sustituido por huacales o botes que se cuelgan para que estén fuera del alcance de los animales domésticos, de tal forma que se crea un espacio cultivable adicional al suelo del solar. El chiquero ( $U$ naj k'éek) es una construcción para alojar a los cerdos. El gallinero (U najiil kaax): Es una construcción para alojar a las gallinas, está hecha de madera o piedra. El pozo (Ch'e'en) era un elemento importante en la composición del solar, ya que proveía de agua a las familias (la región no cuenta con aguas superficiales -más que los cenotes ${ }^{5}$ - por lo que los pozos eran la única forma de proveerse de ella. Actualmente la mayoría de las casas tienen conexión a la red de agua. La batea (Nukuli p'o'o) es un espacio para lavar la ropa y en algunas ocasiones, los utensilios de la cocina; se ubica bajo un gran árbol o bajo un techo de palma de guano. Originalmente, era hecha con el tronco ahuecado de un árbol y actualmente es de cemento, con las mismas características. La letrina (Kuchil ta) es un espacio destinado a realizar las necesidades fisiológicas, es otro elemento que ha evolucionado con el tiempo, ya que en algunos solares actualmente se cuenta con sanitarios conectados a la red de agua.

Actualmente, los materiales que se utilizan para la construcción y habitabilidad de los espacios en el solar son, en algunos casos, difíciles de conseguir ya que el entorno ecológico ha sido alterado en gran medida; también porque las prácticas productivas y comunitarias no se apegan tanto a la tradición (Chico, 1995). El solar maya yucateco se encuentra en un proceso de cambio, algunos autores dicen que está en proceso de desaparición, mientras que otros dicen que se está adaptando a los tiempos modernos. De acuerdo con M. T. Ayllón (2003), dentro de una perspectiva etnográfica, se dice que el sistema tradicional permanece mientras los elementos, relaciones y sus funciones persisten, a pesar de los cambios materiales. Entonces, el solar maya yucateco aún se considera tradicional, ya que la esencia de los usos multifuncionales del espacio permanece (Chico, 1995; Ayllón, 2003; Baños, 2003).

Sin embargo, cabe señalar que los solares mayas no están cambiando o desapareciendo únicamente debido a la "modernidad"; la presencia de la vivienda vernácula ha sido considerada como un signo de atraso social y tipificada como "arquitectura pobre o marginal", considerando únicamente los materiales "no duraderos" o los materiales precarios que han sustituido los materiales originales de la vivienda. El gobierno y la sociedad en general han olvidado algunos de los valores y cualidades de la arquitectura vernácula y los solares: están basados en tecnologías y materiales regionales que podrían llevar a un desarrollo sustentable tanto de la región como de las comunidades; el uso tradicional del solar como parte de la economía familiar podría servir como una estrategia de subsistencia para las familias en condiciones de pobreza; los espacios del solar generan ambientes naturales de calidad y una imagen urbana clara como parte de la identidad regional; y, los solares se establecen en sí mismo como referencias culturales, asociando usos y costumbres con lugares físicos y definidos (Chico, 1995).

\footnotetext{
${ }^{5}$ Del maya dzonot, los cenotes son manifestaciones cársticas, cuya característica es exponer al agua subterránea, que se encuentran distribuidos en la mayor parte de la península de Yucatán. Existen varios tipos de formaciones, abiertos, de tipo bóveda, de paredes verticales, etc. (Antochiw, 2010; Pérez Ceballos y otros, 2007).
} 


\section{Figura 4. Composición del solar maya yucateco}

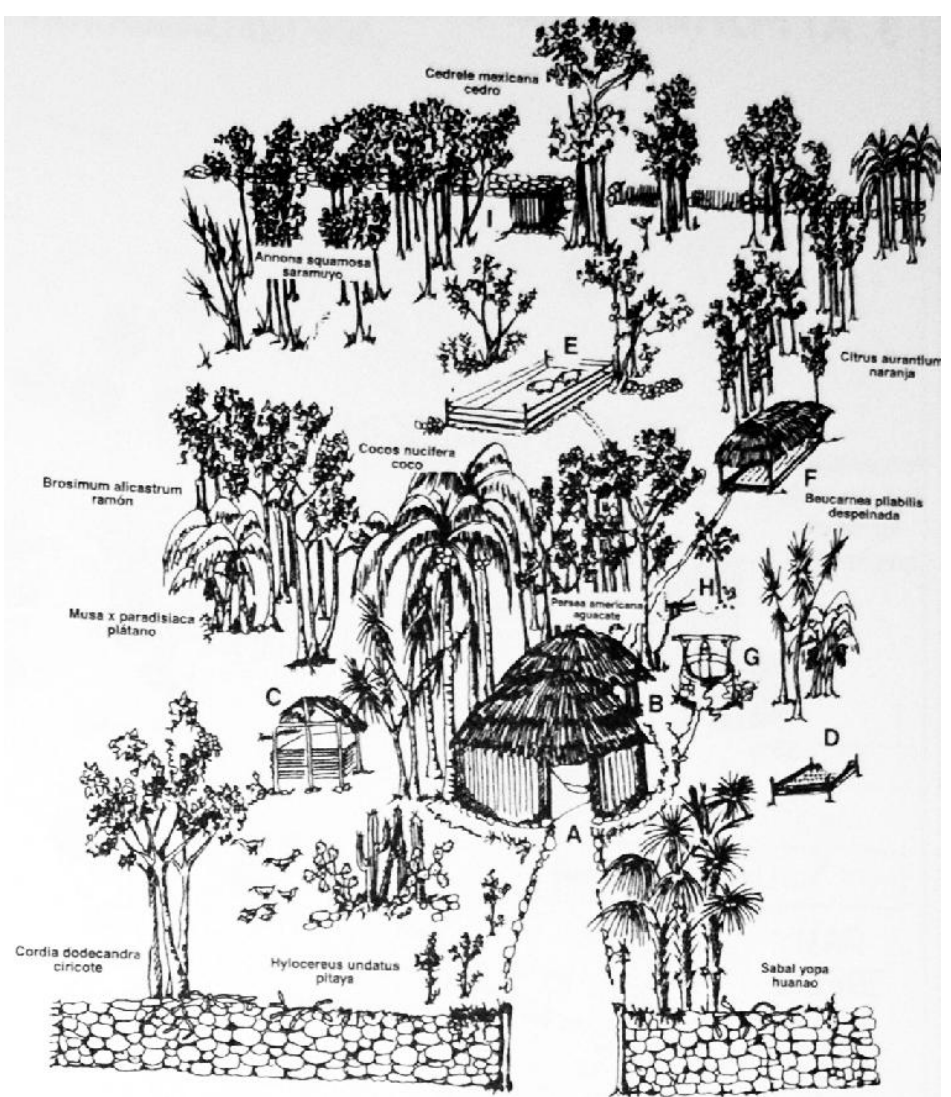

Fuente: Aké Gómez et al. (1999).

\section{La vivienda vernácula maya yucateca}

La casa-habitación del solar es tradicionalmente una vivienda vernácula maya, que data de épocas prehispánicas, producto de una adaptación a las características ambientales y socioculturales de la región, a través de la transmisión de habilidades y conocimientos de generación en generación (Tello, 1999; Baños, 2003) (Fotografía 1). De forma tradicional, la vivienda maya tiene una planta absidal, sin esquinas ${ }^{6}$; los muros son de bajareque cubierto con embarro. Las adaptaciones incluyen plantas rectangulares y muros de mampostería. Únicamente tiene dos aberturas a lo largo, donde se ubican dos puertas, una frente a la otra, de uno por 1.7 metros con puertas dobles que se abaten hacia adentro, que permiten la circulación del aire. El largo aproximado de la vivienda es de nueve metros y el ancho entre cuatro y seis metros. La vivienda se localiza dentro del solar, ya sea al centro del mismo como es tradicional, o al borde de la calle, como es más común (Sánchez, 2006; Román, 2011; Máas, 2011; Sánchez et al, 2011).

\footnotetext{
${ }^{6}$ Ya que según la traducción del Popol Vuh, considerado por algunos como el Libro Sagrado de los mayas, "el demonio habita en las esquinas de las casas” (Román Kalisch, 2011).
} 


\section{Fotografía 1. Vivienda maya yucateca}

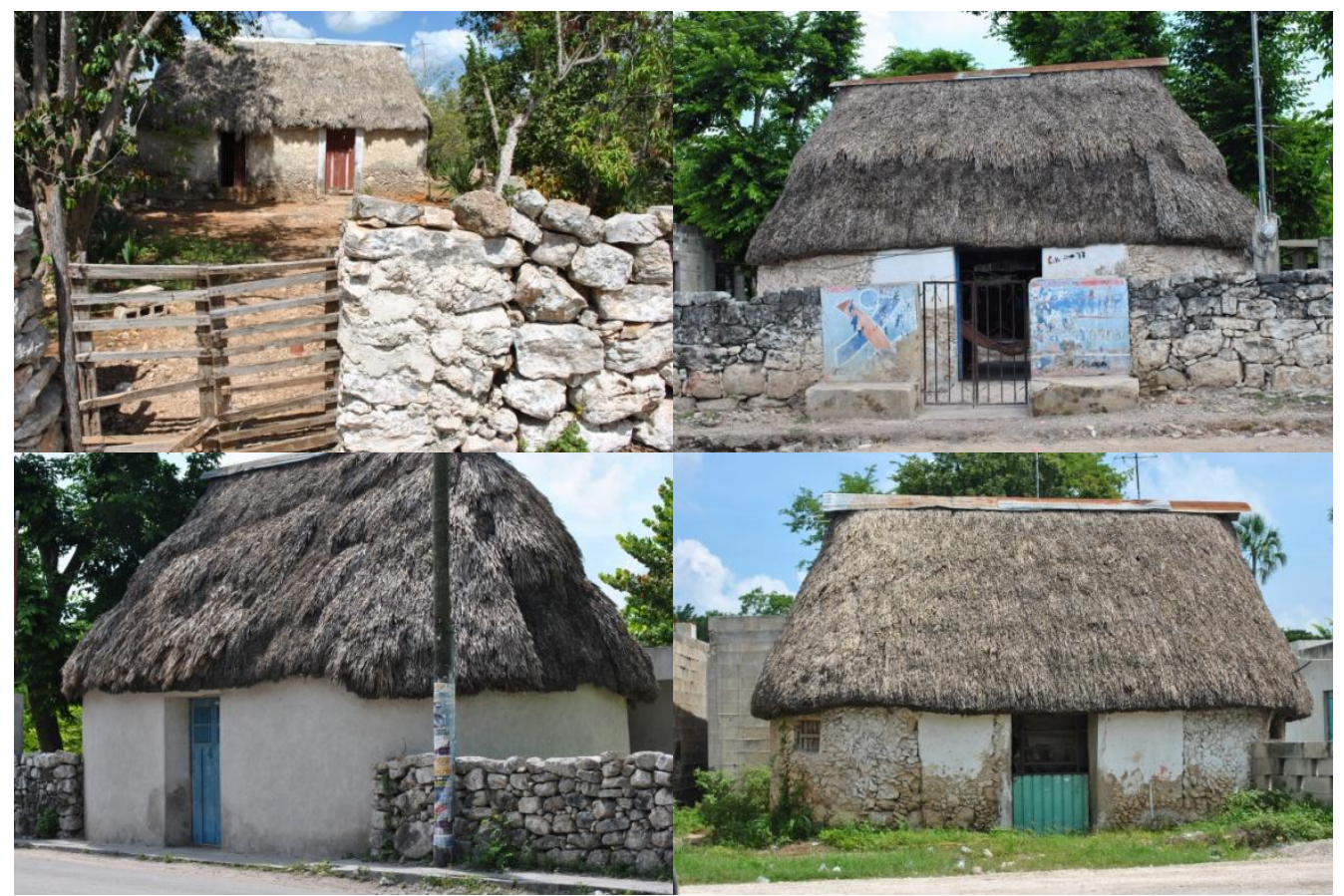

Autora: Ana Julia Cabrera Pacheco (febrero y septiembre de 2011).

La estructura de la vivienda maya está hecha de materiales naturales de la región, encontrados usualmente en el solar o en el monte. Eastmond et al (2011) reportan que se utilizan entre 36 y 45 distintas especies vegetales. El material del techo es la palma de guano ( $x a$ 'an); para su colocación, se sigue la propia estructura de la cubierta. La palma se coloca comenzando desde la parte inferior, traslapando las palmas mientras se colocan, hasta llegar al caballete, que se cubre con zacate $(z u u c)$. Cada vivienda lleva un promedio de 2,200 hojas de guano. Una de las virtudes del techo de palma de guano es que permite que el calor acumulado en la parte superior se disipe en los intersticios de la cubierta vegetal, contribuyendo al confort térmico de la vivienda (Centeno et al., 2005; Sánchez, 2006; Eastmond et al., 2011; Román, 2011).

\section{RESULTADOS}

\section{Medios de vida del solar maya yucateco}

Los medios de vida del solar maya yucateco fueron analizados a nivel de vivienda, identificada como vivienda vernácula a través de la característica de tener un techo de palma de guano. A nivel general, las diferencias entre los resultados de las localidades son notables y no pueden considerarse homogéneos (Figura 5).

Los capitales humano y físico, en particular, mostraron gran diferencia entre sus valores, señalando que las habilidades, destrezas y condiciones de los habitantes para la subsistencia, así como la infraestructura necesaria para satisfacer sus necesidades básicas y ser más 
productivos, dependen de la familia y no de la comunidad como un todo. El capital económico es menos variable y se localiza en un nivel bajo en cuanto a los valores obtenidos y en comparación con los otros capitales. El capital ambiental varía entre los niveles bajo y medio, mientras que el capital social tiene los valores más altos en conjunto. Con respecto a los indicadores, los valores muy bajos se localizan en casi todos los capitales, en el humano: la escolaridad; en el físico: la disponibilidad de refrigerador (nulo en cuatro localidades); en el económico: el índice de dependencia, el total de ingresos y el número de bienes; y en el ambiental: la cobertura de la vegetación (para el municipio de Mérida) y el cultivo de plantas (reportado a nivel localidad en general). Para el año 2010, realizado con fines comparativos, los indicadores de escolaridad, disponibilidad de bienes (incluyendo refrigerador) y el total de ingresos han tenido una mejoría considerable, que es de esperarse que se haya traducido a nivel del solar.

\section{Figura 5. Medios de vida de los solares mayas yucatecos a nivel localidad \\ Medios de vida en solares de la ZMM}

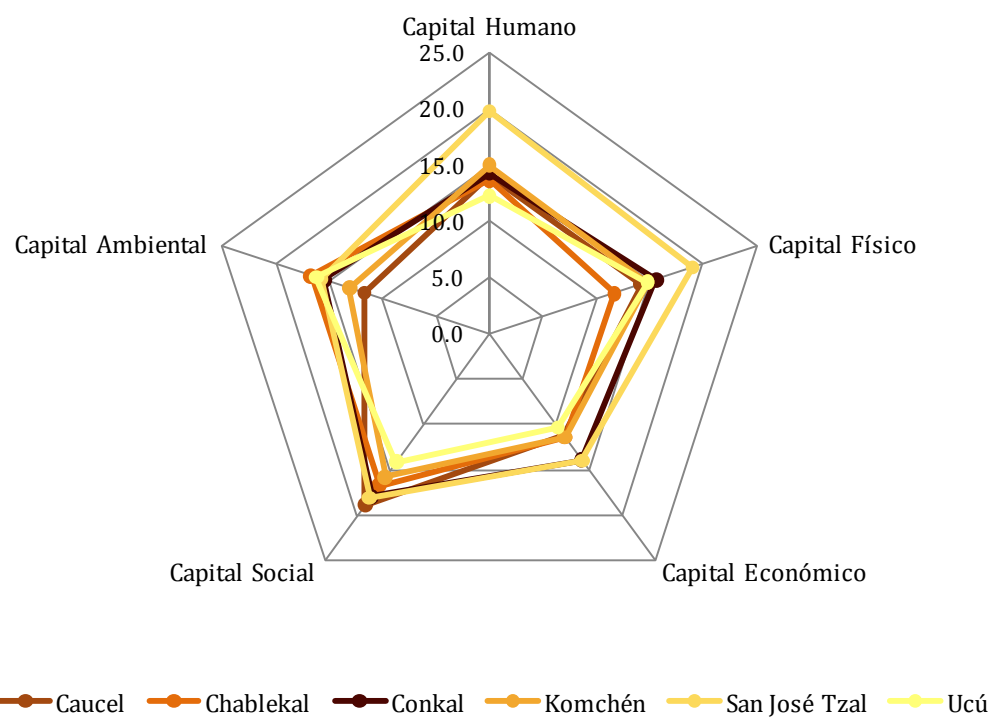

Fuente: Elaboración propia.

Las características de las viviendas en el solar se han dividido en sus características sociales (que incluyen los capitales humano y social), las características económicas (que incluyen los capitales físico y económico) y las características ambientales.

\section{Características sociales}

El solar no se compone únicamente de un módulo de casa-habitación con una familia nuclear, en él se desarrolla principalmente el modelo de familia extensa, que deriva de la tradición que cuando los hijos forman su propia familia, permanecen en el solar, donde construyen una 
nueva vivienda. Aunque duerman en construcciones separadas, comparten los otros espacios y actividades del solar (Tello, 1995; Baños, 2003). De las viviendas analizadas, el 80\% presentaban una distribución de edades que incluyen niños, jóvenes, adultos y adultos mayores, mientras que el $30 \%$ de las viviendas tenían un número de habitantes mayor al promedio.

El solar es fundamentalmente un espacio social complejo, que se corresponde al ámbito familiar, que deciden las funciones que tendrá el espacio. Las actividades de producción son una parte del conjunto de actividades que se delimitan espacialmente y se sustentan en las relaciones sociales. Parte de dichas actividades se extienden fuera del solar, hacia la milpa, los trabajos externos y antes, la educación, realizados por elementos definidos de la familia. Ahora la educación es obligatoria para todos, pero en los demás casos, los habitantes del solar pueden ser elegidos por sus capacidades para dedicarse a alguna u otra actividad. Asimismo, tanto dentro como fuera del solar, se desarrollan relaciones sociales con otras familias, como medio de apoyo (Estrada et al., 1998; Ayllón, 2003). Cuando los solares son habitados únicamente por personas mayores o por jóvenes y niños y adultos mayores, esta capacidad para desarrollar múltiples actividades se pierde, limitando la productividad del solar. El 30\% de los solares analizados presentaba esta característica. La educación presentaba valores muy bajos, apenas en el $15 \%$ de las viviendas más de la mitad de sus habitantes sabían leer y escribir, y en menos del $10 \%$ de las viviendas sus habitantes promediaban una educación superior a la primaria. Para el 2010, ambas situaciones han mejorado, sobre todo los niveles de alfabetismo, al menos a nivel localidad. En cuanto a la lengua indígena, considerada como una destreza positiva ya que refuerza el sentido de la identidad, se transmiten conocimientos y se perpetúa la cultura, los niveles eran altos para el 2000, con el $60 \%$ de las viviendas donde todos sus integrantes la hablaban, y el $25 \%$ donde más de la mitad lo hacían. Sin embargo, para el 2010 esta situación se había revertido a nivel localidad. La derechohabiencia tenía un valor medio, con el 35\% de las viviendas donde sus habitantes no contaban con algún tipo de servicio de salud. Con respecto a los otros indicadores, en el $80 \%$ de las viviendas todos sus habitantes se declararon como parte de una religión; mientras que en dos de las localidades se consideraba que la comunidad era moderadamente organizada, en cuatro localidades sus habitantes reportaban muy bajos índices de criminalidad, e índices medios y medios-altos de percepción de seguridad.

\section{Características económicas}

El solar genera una red de recursos, tanto a nivel ambiental como a nivel económico; la economía "de patio" se refiere a los ingresos económicos extras que se perciben como fruto de la venta de especies que se crían y se cultivan en el solar. La economía está estrechamente relacionada con las relaciones sociales y las actividades que en el solar se realicen, además de los ingresos que los habitantes aportan al trabajar fuera del solar. En el 65\% de las viviendas se recibían ingresos externos, ya sea por trabajo o por pensiones de los adultos mayores, sin embargo, en el $45 \%$ de las viviendas dicho ingreso era inferior a un salario mínimo y únicamente el $20 \%$ de las viviendas tenían un índice de dependencia alto. La disponibilidad de bienes era muy baja, especialmente de refrigerador, únicamente el $10 \%$ de las viviendas poseían uno. 
Para aprovechar al máximo las bondades del solar, éste debe conservarse o mejorarse para que sea capaz de afrontar crisis como las que ocurren durante los huracanes o durante las crisis económicas, cuando el solar debe ser capaz de absorber la mano de obra extra (JiménezOsornio et al., 1999). Durante el huracán Gilberto (1988), la economía familiar se vio mermada al sufrir pérdidas tanto en los solares como en las milpas. Las estrategias de subsistencia incluyeron, el consumo de las reservas y el uso de las reservas de semillas para proveerse lo más pronto posible de alimento (Ayllón, 2003). Durante este huracán, los solares sufrieron además, la pérdida o daño de los techos tradicionales de las viviendas. El apoyo de las instituciones gubernamentales fue encaminado a repartir láminas de cartón para sustituir la palma de guano (Fotografía 2), lo que elimina todas las características propias de la cubierta, encerrando el espacio y concentrando el calor; además que se cree que este material es dañino para la salud (Ayllón, 2003; Román, 2011). El uso de este tipo de materiales, que continuó a través de los años como parte de la "generosidad" de las instituciones gubernamentales, demerita la vivienda, el espacio y a la gente que la habita, además que ha generado una pérdida en la necesidad de ciertos elementos vegetales que han ido desapareciendo paulatinamente de los solares, y que conlleva en cierta medida a la pérdida de elementos productivos en el solar.

Una gran ventaja en la zona es la propiedad de la vivienda (y el solar), que permite a los habitantes disponer de una seguridad patrimonial y planificar a corto, mediano y largo plazo el manejo de sus recursos (Jiménez-Osornio et al., 1999); el 85\% de las viviendas pertenecían a alguno de sus habitantes. El material del piso fue diferente a la tierra en el $95 \%$ de los casos y el hacinamiento no existía en el $60 \%$ de los casos. La disponibilidad de agua entubada reflejaba las costumbres de los habitantes, al no tenerla dentro de la vivienda pero sí en el terreno en el $60 \%$ de los casos, mientras que en el $15 \%$ de los casos se reportó la disponibilidad dentro de la vivienda. Esto podría deberse a una diferente concepción del concepto vivienda, si se refiere al edificio de casa-habitación o incluye también a la cocina. Exceptuando el material del piso, que se mantuvo estable, todos los indicadores del capital físico mejoraron a nivel localidad para el 2010. En el caso del capital económico, los habitantes que aportan ingresos disminuyeron, pero aumentó el total de ingresos por vivienda por lo tanto también la disponibilidad de bienes, la propiedad de la vivienda disminuyó y el índice de dependencia se mantuvo estable.

\section{Fotografía 2. Viviendas con cubiertas de}

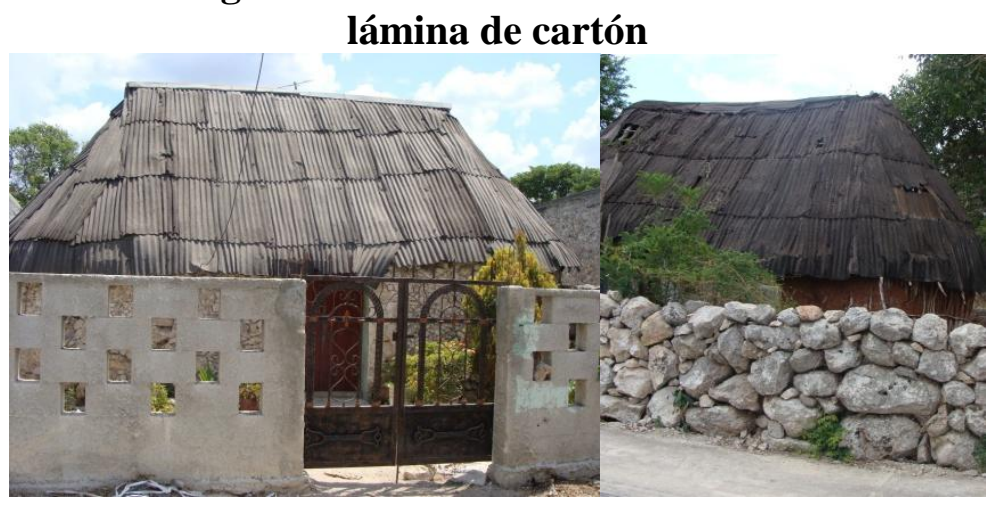

Autora: Ana Julia Cabrera Pacheco (junio de 2011). 


\section{Características ambientales}

La región tiene características ambientales específicas como son la topografía plana, el origen cárstico con ausencia de corrientes de agua superficiales, y tres estaciones: una estación seca, con altas temperaturas y lluvias escasas entre marzo y mayo, una estación de lluvia, con lluvias intensas entre junio y octubre, y una estación de frentes fríos con lluvias ocasionales entre noviembre y febrero. El tipo de vegetación pertenece a la selva baja caducifolia que se desarrolla sobre suelos calizos, delgados y pedregosos. A esto se añade la recurrencia de incendios forestales y la alta frecuencia de huracanes (Schmitter-Soto et al., 2002; Toledo et $a l ., 2008)$. A nivel de vivienda se reportó únicamente un indicador del capital ambiental, los otros cuatro fueron considerados a partir de fuentes a nivel de localidad y de municipio. Únicamente en una localidad se tuvo el nivel de cobertura vegetal considerado como óptimo; la calidad del agua tuvo niveles altos en dos localidades y medio-altos en una; mientras que la acumulación de basura fue reportada con valores similares para las seis localidades, con un valor medio y medio-alto. El uso de combustible natural, la leña, fue considerado como de gran valor ya que se relaciona en gran medida del manejo que se dé en el solar, sin depender de insumos externos que generan costo extra a las familias.

Según algunos estudios, uno de los mecanismos de resiliencia socio-ambientales es la estrategia de uso múltiple de los recursos naturales, sobre todo a nivel de la unidad doméstica, tanto para fines de subsistencia, o autoconsumo, como para el desarrollo del intercambio o del mercado a nivel más bien local. El número de especies de plantas por solar ha sido reportado en promedio entre 50 y 100 especies por vivienda y entre 100 y 200 por comunidad, para todas las regiones yucatecas. Se ha estimado que entre el 70 y el $80 \%$ de estas especies son nativas. Los elementos vegetales del solar son utilizados principalmente como alimento, pero también para usos medicinales, ornamentales, como combustible, y para la construcción de viviendas y herramientas, así como también como forraje para los animales domésticos; muchas de las especies proporcionan diversos productos a lo largo del año y tienen un uso múltiple. (Correa, 1997; Jiménez-Osornio et al., 1999; Toledo et al., 2008). Sin embargo, esta característica no se vio reflejada en los cálculos realizados en el presente estudio; los valores reportados presentan niveles bajos y muy bajos.

\section{Características de la palma de guano (Sabal spp.)}

El solar se describe como un agrosistema dinámico, donde la sustentabilidad es favorecida por la diversidad y asociaciones de sus recursos naturales, es decir, que dichas asociaciones hacen un uso más eficiente de diversos recursos externos como la luz y el suelo. Existen una serie de especies vegetales que se consideran como estructurales, de ellas depende la resiliencia y sustentabilidad del agrosistema. A. Aké et al (1999) identificaron 20 especies a nivel bibliográfico y 11 a nivel de campo (algunos ejemplos, Annona reticulata L. - Cop o anona; Citrus aurantieum L. - K'an-pak'al o naranja agria; Sabal yapa (Wright.) Stand. - Xa'an o palma de guano). Las especies estructurales aportan más del $65 \%$ de la productividad del solar (Jiménez-Osornio et al., 1999).

Las palmas son plantas monocotiledóneas pertenecientes al Orden Areacales y la Familia Arecaceae. Comprenden más de 2,600 especies en aproximadamente 200 géneros. Junto con las gramíneas y las leguminosas constituyen una de las familias más importantes desde el 
punto de vista económico. En la Península de Yucatán existen 20 especies de palmas de 14 géneros, de las cuales, nueve crecen de forma natural. La especie Sabal yapa C. Wright. ex Becc. ( $x a^{\prime}$ 'an en maya) es una de ellas. Esta especie crece de forma silvestre o natural y también asociadas a actividades antrópicas; pertenece al bosque primario y cuenta con la capacidad de adaptarse y desarrollarse en ambientes fuertemente perturbados (Caballero et al., 2001; Pérez y Rebollar, 2008; CICY, 2010; Durán, 2010). La palma de guano es una palma de lento crecimiento y ciclo de vida largo, se estima que un individuo puede vivir cien años o más; el tiempo que tarda en alcanzar la madurez reproductiva es de unos 12 años, mientras que su vida de cosecha se ha estimado en 25 años o más. A pesar que puede ser cosechada todo el año, se acostumbra su cosecha en temporada de secas debido a que se conservan por mayor tiempo, cinco meses, antes de ser utilizadas, en comparación con las que se recolectan en época de lluvias, cinco días (Caballero et al., 2004).

El uso de la palma de guano se remonta hasta antes de la conquista española. Ha proporcionado a los mayas materia prima para diversos usos como proveer alimento, uso medicinal, para fabricar utensilios, como material de construcción y como forraje, entre otros, por más de mil años. El uso de la hoja madura para techar la vivienda vernácula maya, principalmente por su durabilidad, es uno de esos usos (Caballero et al., 2001; Pérez y Rebollar, 2008). El manejo de la palma de guano en los solares tradicionales optimiza el recurso, ya que aunado al reemplazo natural, la población vegetal se incrementa por acción humana de siembra, protección y mantenimiento del micro-hábitat, con condiciones adecuadas de luz y humedad (Caballero et al., 2001). Varios estudios han sugerido que el uso sustentable en manejos tradicionales es posible debido a que dichos sistemas han permanecido a lo largo del tiempo, siendo también que involucran una relación cercana sociedadnaturaleza. El uso sustentable, desde una perspectiva ecológica, se manifiesta cuando el manejo de un recurso permite su reemplazo natural, por lo que es capaz de renovarse a sí mismo indefinidamente. Los análisis demográficos realizados sugieren que el uso tradicional de las palmas de guano es sustentable, considerado en términos de su persistencia a largo plazo y por lo tanto, manteniendo la disponibilidad de las hojas. Sin embargo, la sobreexplotación podría reducir las tasas de crecimiento; mientras que el aumento de la demanda, tanto externa como local, podría derivar en una disminución de la población y en la disponibilidad de hojas (Martínez-Ballesté et al., 2005).

Cabe señalar que el techo de palma de guano, considerado como un símbolo de la pobreza, es utilizado ampliamente para infraestructura turística, tanto en la ZMM como en el Estado y la Península de Yucatán. En algunos medios se tiene conocimiento de la existencia de "reservas" de palmas de guano donde no permiten que las familias de las comunidades cercanas aprovechen el material para sus viviendas, sino que el objetivo es venderlo a los centros de turismo de la región, beneficiando económicamente a unos cuantos. La industria turística ha aumentado el mercado de la palma de guano, que pasa de ser un producto tradicionalmente doméstico, a ser una posible fuente de ingresos para los habitantes de los solares. La oferta de hoja de las principales comunidades forestales mayas del Estado de Quintana Roo en la Península de Yucatán, era de aproximadamente 200,000 hojas por año, que podían representar un ingreso extra para los habitantes de los solares de aproximadamente 180,000 pesos mexicanos (Caballero et al., 2004). En las localidades yucatecas, la hoja de la palma de guano se comercializa, aproximadamente, en 1 o 2 pesos mexicanos, mientras que en la Riviera Maya, ésta llega a tener un valor de 4 a 5 pesos mexicanos (Eastmond et al., 2011). 
Con el paso de los años, el impacto que la comercialización de la palma de guano no se ha traducido en la pérdida de la sustentabilidad a nivel solar ni en la generación de beneficios económicos representativos (Caballero et al., 2004). La pérdida de sustentabilidad se ha dado a nivel cultural ya que debido a los cambios y transiciones socio-culturales ya descritas, el conocimiento biológico y la importancia de la percepción cultural modifican las prácticas de manejo, disminuyendo la base del recurso. En un estudio realizado por Martínez-Ballesté et al., (2006), se observó que la densidad de la palma es mayor en los solares más tradicionales (hasta 900 palmas por hectárea), que en los solares con mayores cambios culturales (no más de 200 palmas por hectárea). Los solares tradicionales se identifican por el mayor uso de la palma de guano para techas sus viviendas y otros espacios, como cocinas, letrinas, etc. que al requerir más hojas, promueven el aumento de la disponibilidad de palmas.

\section{Desaparición de la vivienda vernácula y su impacto en el solar}

En general, a nivel de la sociedad y de las instituciones gubernamentales de la región, el solar y su vivienda vernácula son catalogados como de un nivel social inferior y son percibidos como un símbolo de pobreza, insalubridad y disfuncionalidad (Gobierno de Yucatán, 2004; Sánchez, 2006). Esta idea es transmitida y adoptada muchas veces por los propios integrantes de los solares, quienes se perciben como "pobres" por el hecho de vivir en una vivienda maya. En los últimos años, por ejemplo, el gobierno del Estado ha manifestado el valor que tiene la cultura maya y ha desarrollado algunas acciones para dar a conocerla al mundo. Sin embargo, una de las principales representaciones actuales de la cultura y la sociedad maya es el espacio donde viven, el solar y la vivienda mayas, y éstos no han sido tomados en cuenta. Las instituciones gubernamentales no cuentan con acciones en beneficio de la vivienda maya y del

solar, o desconocen si existen, siendo que únicamente se promueven dichas acciones para las viviendas "modernas" (Indemaya, 2011).

Cuando se recorren las localidades de la ZMM se constatan los cambios descritos en la literatura, sobre la adopción de viviendas más "urbanas" o de materiales industriales para adaptar la vivienda maya dentro del solar. Además de ser un reflejo de los cambios culturales que sufre la sociedad maya tradicional, se observan también las intervenciones de las instituciones gubernamentales que han contribuido en este proceso. Un ejemplo de estas acciones que quizá es la que mayor impacto ha tenido en las últimas décadas fue la respuesta gubernamental a la crisis ocasionada por el paso del huracán Isidore en 2002. Este fenómeno meteorológico, que alcanzó la categoría 3 de la escala Saffir-Simpson, destruyó las viviendas y los medios de vida de los habitantes de más de 200 localidades en el Estado de Yucatán. Hubo aproximadamente 83,500 viviendas dañadas, en el 23\% de todas las localidades del Estado; de éstas, el 26\% sufrieron un "daño total” (Bitrán et al., 2003). La mayor parte de las casas afectadas fueron vernáculas mayas (Fotografía 3). 


\section{Fotografía 3. Viviendas tradicionales con daños parciales y totales en el techo}

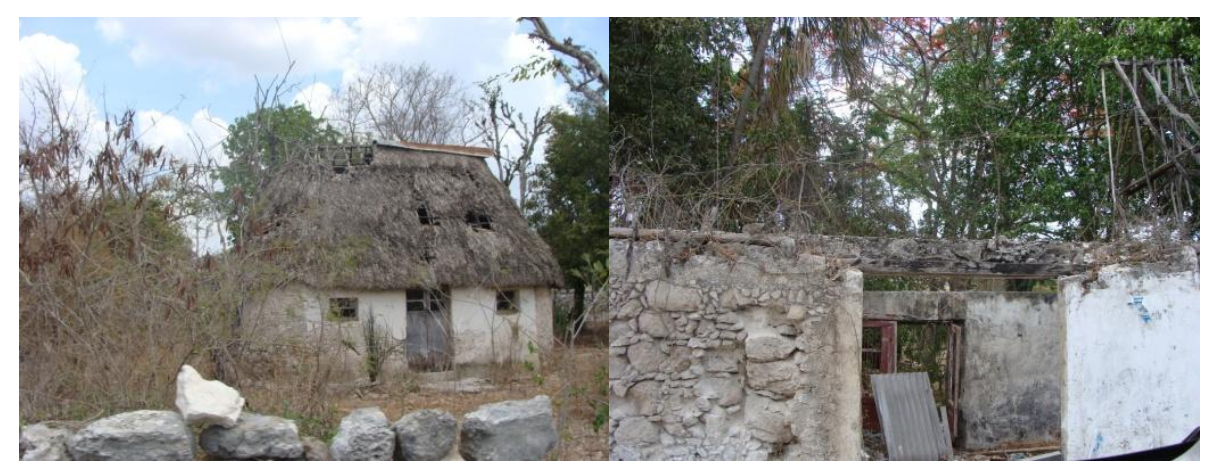

Autora: Ana Julia Cabrera Pacheco (junio de 2011).

Después del huracán, los gobiernos federal y estatal, a través del programa federal Fondo de Desastres Naturales (FONDEN), construyeron "pies de casa", que son consideradas como unidades básicas de vivienda, con un baño y espacio para la cocina o estufa, de materiales industrializados: bloques de concreto, piso de cemento pulido y techo de lámina metálica. Incluye también puertas, ventanas, electricidad, agua entubada y sistema de drenaje. Según información del Instituto Estatal de Acceso a la Información Pública (INAIP), al diseñar el modelo de "pie de casa" deben respetarse los "usos y costumbres" de la región (INAIP, 2007), lo que no sucedió en este caso, ya que los materiales no fueron respetados, los sistemas de drenaje son deficientes según las características de la región y la costumbre de la localización de la vivienda fue alterada, a pesar de que los usuarios insistieron en ello: la vivienda vernácula se ubica con el lado "largo" paralelo a la calle, de modo que las puertas queden frente a ella; los "pies de casa" fueron construidos en sentido inverso con una puerta en el lado angosto. Otra costumbre que no se tomó en cuenta fue la tradición de que en el mismo solar se asienten varias viviendas de la familia extensa; por indicación de las administraciones locales, los jefes de familia tuvieron que dividir su terreno, física y legalmente, para que se les otorgaran varias viviendas en el solar. En muchos lugares, estas viviendas (Fotografía 4), han sido adaptadas, modificadas y ampliadas; en algunos casos, los propios habitantes reconstruyeron viviendas vernáculas y utilizan los "pies de casa" como bodegas o futuros refugios contra huracanes. Algunas familias jóvenes se han apropiado de las casas Fonden por la imagen menos tradicional que presentan, pero aún hacen uso del solar compartiendo con su familia extensa (Torres, 2011).

Al desaparecer la vivienda vernácula, la palma de guano tiende a desaparecer, alterando la biodiversidad del solar. Al haber procesos culturales de cambio, el solar pierde su importancia como proveedor de recursos y como centro de actividades sociales, económicas y culturales. La palma de guano ha probado ser sustentable ecológicamente en su manejo tradicional, por lo que una reactivación de su uso como parte de la vida diaria de los habitantes del solar, garantiza su recuperación, lo que podría repercutir en un beneficio económico si se desarrollaran políticas públicas para hacer de la palma de guano sustentable un elemento atractivo para el mercado turístico regional. 


\section{Fotografía 4. "Pies de casa" (Fonden)}

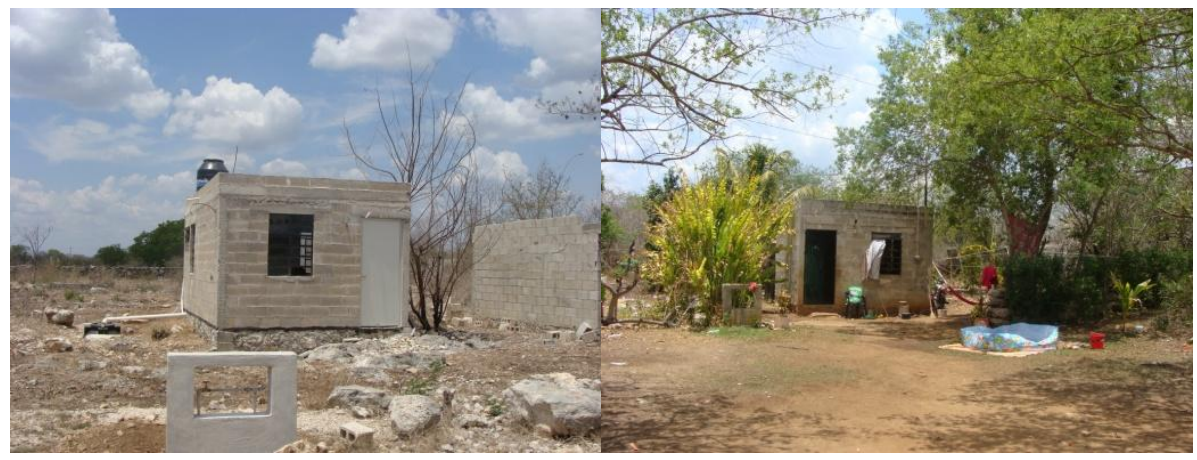

Autora: Ana Julia Cabrera Pacheco (junio de 2011).

El marco de los medios de vida sustentables presenta un enfoque complejo e inclusivo para determinar la sustentabilidad del solar maya yucateco. La relación de dicha complejidad con el uso de la palma de guano aporta un enfoque tanto ambiental como social y económico. Sin embargo, dado que los indicadores utilizados para determinar los medios de vida son muy diferentes entre sí, los futuros estudios sobre el tema deben realizar una valoración previa sobre el alcance y el impacto del uso de los distintos indicadores. El análisis de los procesos de valoración de cada uno de los indicadores también debe tomarse en cuenta, ya que se mezclan valores cualitativos y cuantitativos que deben agregarse para ser comparables a cierto nivel. El papel que desempeñan los propios habitantes de los solares y de las viviendas vernáculas, así como la sociedad civil será fundamental para la recuperación de la sustentabilidad en estos espacios y el desarrollo congruente entre lo social, lo ambiental y lo económico, esto es por ejemplo, un incremento en la alfabetización de las comunidades mayas sin que por eso conlleve la perdida de la propia lengua maya. La degradación sin conocimiento de estos espacios no solo daña a los actuales representantes de la cultura maya, sino que dañan la continuidad de la reproducción social y ambiental de este grupo específico de población.

\section{CONCLUSIONES}

Los cambios que ha presentado la zona metropolitana de Mérida, derivados del crecimiento y la "urbanización" de los espacios rurales, han impactado el modo de vida de las comunidades mayas yucatecas. En el sentido positivo, la población de las localidades periurbanas tiene un mejor acceso al sistema de agua entubada, a la educación y otras mejoras físicas y económicas, principalmente. Sin embargo, la población ha perdido parte de su identidad al reducirse el número de hablantes de lengua indígena y al cambiarse el tipo de vivienda tradicional por una "moderna", perdiendo los usos y actividades sociales y económicas practicadas en el solar por la familia. En la ZMM, se ha confirmado que la vivienda vernácula ha desaparecido casi en su totalidad, tanto en la zona conurbada como en la periurbana, y se sospecha que no es predominante, ni siquiera, en la zona rural. 
Las instituciones gubernamentales han influido en algunos de estos cambios al no tener la suficiente sensibilidad cultural para apoyar a la población en momentos de crisis y al demeritar su estilo de vida en comparación con el estilo de vida urbano de las ciudades. Una de las pérdidas más impactantes es la del techo tradicional basado en el cultivo sustentable de la palma de guano (Sabal spp.). Los solares tradicionales presentaban la vivienda como parte del mismo: una cubierta vegetal en un entorno vegetal, cuyo cambio no sólo ha afectado las relaciones que se dan en el solar, sino que también se ha alterado el entorno o imagen de las localidades mayas yucatecas. La disminución de la familia extensa en el solar y la pérdida de la lengua maya dificultarán la recuperación de la palma de guano en el solar; mientras que una educación integral, la permanencia de una cobertura de vegetación alta y el desarrollo de cultivos de auto-consumo, probablemente coadyuvarían dicha recuperación.

Los medios de vida sustentables del solar deben ser analizados a mayor profundidad, sobre todo en la ZMM, de forma que se planteen políticas públicas adecuadas dirigidas a revalorar la cultura maya dentro de la sociedad yucateca, y no únicamente como un producto turístico. La recuperación de la palma de guano en el solar, si se genera en un marco comunitario e incluyente, de modo que presente opciones viables para recuperar la vivienda vernácula y posiblemente genere ingresos a sus habitantes, se presenta como una alternativa sustentable para desarrollar dichas políticas públicas, cuyo fin sea ayudar a las familias mayas a recuperar su identidad y a tener una vida digna dentro de su cultura y estilos de vida. La existencia generalizada de la techumbre de palma de guano podría influir en la propia percepción de los espacios que las comunidades mayas habitan. Una re-educación de la sociedad y del gobierno yucateco es necesaria para comprender que la diferencia entre los estilos de vida es valiosa y debe respetarse. La vivienda maya yucateca y la vida en el solar no son precarias en sí mismas, se hacen precarias cuando sus habitantes no son tomados en cuenta y no se les permite opinar sobre la forma en que quieren vivir su vida y llevar a cabo sus tradiciones.

El fin último del desarrollo sustentable es la mejora de la calidad de vida de los habitantes de la región, por lo que deben comprenderse quiénes son los que habitan el territorio, cómo lo habitan y cómo afectarán a su modo de vida los cambios que quieran realizarse, teniendo en cuenta que los sistemas de administración actual dependen de la participación pública y el desarrollo de la gobernanza para alcanzar objetivos comunes.

\section{BIBLIOGRAFÍA}

AKÉ GÓMEZ, A., JIMÉNEZ-OSORNIO, J. y RUENES MORALES, M. El solar maya. En: CHICO PONCE DE LEÓN, P. (Ed.). Atlas de Procesos Territoriales de Yucatán. Mérida: Universidad Autónoma de Yucatán, 1999.

ANZALDO, C. y PRADO, M. Índice de marginación a nivel localidad 2005. México D.F.: Consejo Nacional de Población, 2007.

ÁVILA SÁNCHEZ, H. Periurbanización y espacios rurales en la periferia de las ciudades. Estudios Agrarios (Procuraduría Agraria), 2009, nº 41, p. 93-123. 
AYLLÓN TRUJILLO, M. T. La intersección Familia, Identidad y Territorio. Estrategias familiares en un entorno rural de fuerte migración: Yucatán a finales del siglo XX. Tesis doctoral. Madrid: Universidad Complutense de Madrid, 2003.

BAÑOS RAMÍREZ, O. Hamaca y cambio social en Yucatán. Revista Mexicana del Caribe, 2003, vol. VIII, p. 169-214.

BITRÁN BITRÁN, D., DOMÍNGUEZ MORALES, L., DURÁN HERNÁNDEZ, R., FUENTES MARILES, O., GARCÍA ARRÓLIGA, N., JIMÉNEZ ESPINOSA, M., LÓPEZ BÁTIZ, O., MATÍAS RAMÍREZ, L. G., REYES SALINAS, C., SALAS SALINAS, M. A. y ZEPEDA RAMOS, O. Impacto socioeconómico de los principales desastres ocurridos en la República Mexicana en el año 2002. Serie: Impacto Socioeconómico de los desastres en México, 2003. [En línea]. en: $<$ http://www.proteccioncivil.gob.mx/work/models/ProteccionCivil/Resource/375/1/images/no 4.pdf $>$. [Consultado: 08.03.2011].

BRACAMONTE y SOSA, P. y LIZAMA QUIJANO, J. Marginalidad indígena: Una perspectiva histórica de Yucatán. Desacatos (Centro de Investigaciones y Estudios Superiores en Antropología Social, 2003, nº 013, p. 83-98.

CABALlERO, J., TERESA PULIDO, M. y MARTÍNEZ-BALLESTÉ, A. El uso de la palma de guano (Sabal yapa) en la industria turística de Quintana Roo, México. En: ALEXIADES, M. y SHANLEY, P. (Eds.). Productos forestales, medios de subsistencia y Conservación. Estudios de caso sobre sistemas de manejo de productos forestales no maderables. Jakarta: Centro para la Investigación Forestal Internacional, 2004.

CABALLERO NIETO, J., MARTÍNEZ, A. y GAMA, V. 2001. El uso y manejo tradicional de la palma de guano en el área maya de Yucatán. Biodiversitas (CONABIO), 2001, nº 39, p. $1-6$.

CABRERA PACHECO, A. J. Teoría del Desarrollo Sustentable. Módulo 3: Teoría del Desarrollo Sustentable. Diplomado de Especialista en Gestión Ambiental Urbana, 2011.

CENTENO LARA, R., CERÓN CARDEÑA, M. y RODRÍGUEZ PÉREZ, I. Comportamiento estructural de la casa maya ante vientos huracanados. Cuadernos de Arquitectura de Yucatán, 2005, n² 23, p. 64-71.

CHICO PONCE DE LEÓN, P. La arquitectura vernácula de la zona conurbada de la ciudad de Mérida, Yucatán. En: TELLO PEÓN, L. (Ed.). Proyecto La problemática habitacional de Mérida y su zona conurbada. Mérida: Universidad Autónoma de Yucatán, 1995.

CORREA NAVARRO, P. La agricultura de solar en la zona henequenera yucateca. Su evolución y sus posibilidades de mejoramiento productivo. Tesis de maestría. Chapingo: Universidad Autónoma Chapingo, 1997.

CORTÉS, F. y HERNÁNDEZ-LAOS, E. Medición de la pobreza. Demos, 2002. no 15, p. 7-9. 
DELGADO, J., GALINDO, C. y RICÁRDEZ, M. La difusión de la urbanización o cómo superar la dicotomía rural-urbana. En: DELGADO, J. (Ed.). La urbanización difusa de la Ciudad de México. México, D.F.: Instituto de Geografía y Universidad Nacional Autónoma de México, 2008.

DURÁN GARCÍA, R. Palmas. En: DURÁN, R. y MÉNDEZ, M. (Eds.). Biodiversidad y Desarrollo Humano en Yucatán. Mérida: CICY, PPD-FMAM, CONABIO y SEDUMA, 2010.

EASTMOND, A., GARCÍA QUINTANILLA, A. y SÁNCHEZ SUÁREZ, A. La casa maya ante el cambio climático global. Simposio Pasado y presente de la casa de los mayas. 3er Congreso Internacional de la Cultura Maya. Mérida, 2011.

ESTRADA LUGO, E., BELlO BALTAZAR, E. y SERRALTA PERAZA, L. Dimensiones de la etnobotánica: el solar maya como espacio social. En: CUEVAS S., J. A., CEDILLO P., E., MUÑOZ O., A. y VERA C., P. (Eds.). Lecturas en Etnobotánica. Publicaciones del Programa Nacional de Etnobotánica. Chapingo: Universidad Autónoma Chapingo, 1998.

GARCÍA SILBERMAN, A. Indicadores Urbanos de la Zona Metropolitana de Mérida, versión 2011. En: OBSERVATORIO METROPOLITANO DE YUCATÁN (Ed.). Informe parcial. Mérida: Centro de Investigación y de Estudios Avanzados del Instituto Politécnico Nacional-Unidad Mérida, Fomix-Conacyt y Gobierno del Estado de Yucatán, 2011.

Gobierno del Estado de Yucatán. Programa Estatal de Desarrollo del Pueblo Maya 20012007. Mérida: Diario Oficial del Subcomité Estatal Étnia Maya, 2004.

GONZÁLEZ-JÁCOME, A. Ambiente y cultura en la agricultura tradicional en México: Casos y perspectivas. Ciencia Ergo Sum, 2004, vol. 11, nº 2, p. 153-163.

JIMÉNEZ-OSORNIO, J., RUENES MORALES, M. y MONTAÑEZ ESCALANTE, P. Agrodiversidad de los solares de la península de Yucatán. Revista Red. Gestión de Recursos Naturales, 1999 , p. 30-40.

MÁAS COLLÍ, H. Nacimiento y pertenencia en la casa maya. Simposio Pasado y presente de la casa de los mayas. 3er Congreso Internacional de la Cultura Maya. Mérida, 2011.

MARTÍNEZ-BALLESTÉ, A., MARTORELL, C. y CABALLERO, J. Cultural or ecological sustainability? The effect of cultural chanfe on Sabal palm management among the lowland Maya of Mexico. Ecology and Society, 2006, vol. 11, $\mathrm{n}^{\mathrm{o}}$ 2. [En línea]. Disponible en: $<$ http://www.ecologyandsociety.org/vol11/iss2/art27/>.

MARTÍNEZ-BALLESTÉ, A., MARTORELL， C., MARTÍNEZ-RAMOS， M. y CABALLERO, J. Applying Retrospective Demographic Models to Assess Sustainable Use: the Maya Managament of Xa'an Palms. Ecology and Society, 2005, vol. 10, nº 2. [En línea]. Disponible en: 〈http://www.ecologyandsociety.org/vol10/iss2/art17/>.

PACHECO ÁVILA, J. G. Reserva hidrogeológica para el abastecimiento de agua con calidad a la Zona Metropolitana de Mérida. Informe Parcial. Mérida: Universidad Autónoma de Yucatán, Fomix-Conacyt y Gobierno del Estado de Yucatán, 2011. 
PACHECO ÁVILA, J. G. y CABRERA SANSORES, S. A. Calidad del agua subterránea en los sistemas de abastecimiento de agua potableen las comisarías del municipio de Mérida, Yucatán, México. Informe Técnico. Mérida: Universidad Autónoma de Yucatán, Dirección de Obras Públicas del Ayuntamiento de Mérida, Conacyt y SISIERRA, 2001.

PÉREZ GARCÍA, M. y REBOLLAR DOMÍNGUEZ, S. Formas de aprovechamiento de algunas palmas de la Península de Yucatán. Contactos, 2008, nº 69, p. 53-60.

REVILLA, Z. y REYES, A. Conceptos sobre desarrollo sustentable. Documento Interno del Proyecto Alfa de la Red ELAN. Maestría Internacional en Desarrollo y Gestión Sustentables. Universidad de San Martín de Porres, Perú, 2005.

ROBLES-ZAVALA, E. y FIECHTER RUSSO, T. Qualitative study of perceptions on poverty and present status of assests in a Mayan community in the Yucatan Peninsula. Universidad y Ciencia, 2008, vol. 24, nº 003, p. 191-204.

ROMÁN KALISCH, A.El proceso de cambio cultural y tecnológico en la arquitectura vernácula de Yucatán. Simposio Pasado y presente de la casa de los mayas. 3er Congreso Internacional de la Cultura Maya. Mérida, 2011.

SÁNCHEZ SUÁREZ, A. La casa maya contemporánea. Península, 2006, nº 1, p. 81-106.

SÁNCHEZ SUÁREZ, A., EASTMOND, A. y GARCÍA QUINTANILLA, A. La casa maya: de los símbolos contemporáneos a la forma y aspectos constructivos. Simposio Pasado y presente de la casa de los mayas. 3er Congreso Internacional de la Cultura Maya. Mérida, 2011.

SCHMITTER-SOTO, J. J., COMÍN, F. A., ESCOBAR-BRIONES, E., HERRERASILVEIRA, J., ALCOCER, J., SUÁREZ-MORALES, E., ELÍAS-GUTIÉRREZ, M., DÍAZARCE, V., MARÍN, L. E. y STEINICH, B. Hydrogeochemical and biological characteristics of cenotes in the Yucatan Peninsula (SE Mexico). Hydrobiologia, 2002, vol. 467, $\mathrm{n}^{\mathrm{o}}$ 1-3, p. 215-228.

SEDESOL, CONAPO e INEGI. Delimitación de las zonas metropolitanas de México. México, D.F.: Secretaría de Desarrollo Social, Consejo Nacional de Población e Instituto Nacional de Estadística y Geografía, 2004. [En línea]. Disponible en: <http://www.inegi.gob.mx/est/contenidos/espanol/metodologias/otras/zonas_met.pdf $>$.

[Consultado: 26.07.2011].

TELLO PEÓN, L. La vivienda maya: persistencia de la tradición vernácula. En: PERAZA GUZMÁN, M. T. (Ed.). Procesos territoriales de Yucatán. Mérida: Universidad Autónoma de Yucatán, 1995.

TELlO PEÓN, L. Vivienda. En: CHICO PONCE DE LEÓN, P. (Ed.). Atlas de Procesos Territoriales de Yucatán. Mérida: Universidad Autónoma de Yucatán, 1999.

TOLEDO, V., BARRERA-BASSOLS, N., GARCÍA-FRAPOLLI, E. y ALARCÓNCHAIRES, P. Uso múltiple y biodiversidad entre los mayas yucatecos (México). Interciencia, 2008, vol. 33, nº 5, p. 345-352. 
TORRES PÉREZ, M. E. Vivienda vernácula maya en Yucatán: vigencia y riesgo de un modo de vida. Simposio Pasado y presente de la casa de los mayas. 3er Congreso Internacional de la Cultura Maya. Mérida, 2011.

\section{RECURSOS ELECTRÓNICOS}

BANXICO. Principales indicadores salariales de México. Documento de referencia, 2009. [En línea]. Disponible en: <http://www.banxico.org.mx/politica-monetaria-einflacion/material-de-referencia/\%7B1CE5E796-10EA-2044-BFBB-

264B3B4487F8\%7D.pdf>.

BARTRA, A. Los apocalípticos y los integrados. Indios y campesinos en la encrucijada. Memoria Visual. Revista Mensual de Política y Cultura, 2005. [En línea]. Disponible en: $<$ http://www.aporrea.org/actualidad/a11785.html >. [Consultado: 02.08.2011].

CICY. Flora de la Península de Yucatán. Centro de Investigación Científica de Yucatán, A.C., 2010. [En línea]. Disponible Disponible <http://www.cicy.mx/sitios/flora\%20digital/indice_tax_especies.php?genero=Sabal >. [Consultado: 10.09.2011].

COMEY. El Fenómeno Metropolitano. Coordinación Metropolitana de Yucatán, 2007-2012. [En línea]. Disponible en: <http://www.comey.yucatan.gob.mx/articulos_files/FENOMETROPOLITANO.pdf>. [Consultado: 26.07.2011].

DFID. Hojas orientativas sobre los medios de vida sostenibles. Department for International Development, 1999. [En línea]. Disponible en: <http://community.eldis.org/.59c21877/SPGS1.pdf>. [Consultado: 02.08.2011].

GOOGLE. Google Maps: Europa Technologies, Google, INEGI y LeadDog Consulting, 2011. Disponible en: <http://maps.google.com.mx/maps?q=mapa+mexico\&ll=24.166802,$102.480469 \& \mathrm{spn}=21.03089,35.595703 \&$ oe $=u t f-8 \& \mathrm{client}=$ firefox $-\mathrm{a} \& \mathrm{gl}=\mathrm{mx} \& \mathrm{z}=5>$ >

INAIP. Recurso de Inconformidad. Expediente 199/2007. Instituto Estatal de Acceso a la Información Pública, 2007. [En línea]. Disponible en: <http://inaipyucatan.org.mx/Transparencia/Portals/0/pdf/recursosinconformidad/2007/19907. pdf>. [Consultado: 08.03.2011].

INDEMAYA. Rehabilitación o mejora de viviendas tradicionales mayas o sus solares, 2011. Correspondencia electrónica con la autora.

INEGI. XII Censo General de Población y Vivienda. Datos a nivel registro. Instituto Nacional de Estadística y Geografía, 2000.

INEGI. Censo de Población y Vivienda 2010. Principales resultados por localidad (ITER) [En línea]. Instituto Nacional de Estadística y Geografía, 2010a. Disponible en: $<$ http://www.inegi.org.mx/sistemas/consulta_resultados/iter2010.aspx $>$. [Consultado: 22.02 2013]. 
OMY. Primera Encuesta Metropolitana 2010. Datos a nivel registro. Mérida: Observatorio Metropolitano de Yucatán y Cinvestav-Unidad Mérida, 2010.

OMY. Mapa de la Zona Metropolitana de Mérida. Diseño SIG y Cartográfico de Montejo Rubio, Eduardo. Mérida: Observatorio Metropolitano de Yucatán y Cinvestav-Unidad Mérida, 2010.

ONU. El Medio Ambiente. Documentación de las Naciones Unidas: Guía de Investigación. Nueva York: Organización de las Naciones Unidas, 1995-2011. [En línea]. Disponible en: $<$ http://www.un.org/depts/dhl/spanish/resguids/specenvsp.htm $>$. [Consultado: 04.09.2011].

SCT. Rutas punto a punto [En línea]. Secretaría de Comunicaciones y Transporte, 2011. Disponible en: $\langle$ http://aplicaciones4.sct.gob.mx/sibuac internet/ControllerUI?action=cmdEscogeRuta $>$. [Consultado: 27.07 2011].

STEWART CARLONI, A. Guía rápida para misiones. Analizar las instituciones locales y los medios de vida. Instituciones para el Desarrollo Rural, 2006. [En línea]. Disponible en: <http://www.fao.org/docrep/009/a0273s/a0273s00.htm\#Contents>. [Consultado: 02.08.2011].

UN-HABITAT. Urban Indicators Guidelines. Nairobi: United Nations Human Settlements Programme, 2009. [En línea]. Disponible

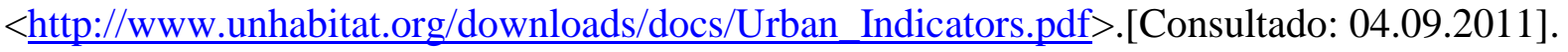

(C) Copyright Ana Julia Cabrera Pacheco, 2014.

(C) Copyright GeoGraphos, 2014.

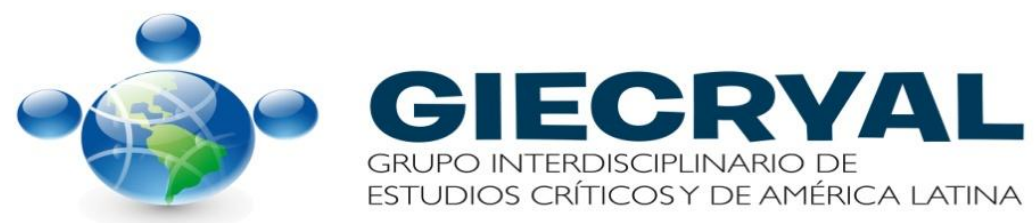

